\title{
PART 2: THE THIRD INTERNATIONAL RADIOCARBON INTERCOMPARISON (TIRI)
}

\section{THE THIRD INTERNATIONAL RADIOCARBON INTERCOMPARISON (TIRI)}

TIRI was officially launched at the 14th International Radiocarbon Conference in Arizona in 1991. Prior to the conference, 150 laboratories received a letter describing the general intention to organize an intercomparison and over 90 laboratories from around the world responded positively to the invitation to participate. Simply stated, the aims of this intercomparison were:

1. To function as the third arm of the quality assurance (QA) procedure.

2. To provide an objective measure of the maintenance and improvement in analytical quality.

3. To assist in the development of a "self-help" scheme for participating laboratories.

TIRI followed through on previous intercomparisons, including that organized by IAEA for the launch of 6 new reference materials, C1-C6 (Rozanksi et al. 1992), and the International Collaborative Study (Scott et al. 1990).

\subsection{Structure of TIRI}

A total of 13 different samples were collected and prepared for TIRI. They were classified as either core or optional. Every laboratory received 6 core samples. The remaining 7 samples were of a more specialized nature; therefore, laboratories were allowed to choose the samples they wished to receive.

Core samples were dispatched to laboratories in March 1992 with results expected by March 1993. The optional samples were dispatched in May 1993 at the same time as a preliminary report on the core results.

\subsection{Sample Selection and Preparation}

The samples used in TIRI were natural, and generally required full laboratory processing, including pretreatment. They were also selected with the following criteria in mind:

- There should be sufficient quantity of material available to meet requirements.

- They should be of archaeological and geological interest.

- They should cover the broad spectrum of laboratory experience.

- They should satisfy rigorous homogeneity conditions.

In some instances, the sample had undergone some preparation before dispatch, and where necessary, had been homogeneity tested.

The range of ${ }^{14} \mathrm{C}$ activities of the samples spanned from "modern" to "close to background," although the majority of samples were clustered in the range of 1000 to $15,000 \mathrm{yr}$.

\section{SAMPLES AVAILABLE IN TIRI}

\subsection{Core Samples}

Each sample was identified by a name and a code. Detailed information was provided concerning each sample. The approximate sample ages were broadly categorized as a rough guide for laboratories in the following way: 
Table 2.1 Sample age classification used

\begin{tabular}{l} 
Modern \\
Less than 1 half-life \\
Between 1 and 2 half-lives \\
Between 2 and 3 half-lives \\
Greater than 3 half-lives \\
\hline
\end{tabular}

\subsubsection{Glengoyne Barley Mash, Sample A}

Age: Modern

Composition/Provenance: This core sample in the series of TIRI standards comprises a barley grain by-product from the manufacture of malt whiskey.

As a first stage in malt whiskey distillation, barley grains are allowed to sprout to catalyze the conversion of the constituent starch to sugars. This "malted" barley is mixed with water to produce a "mash", which is allowed to ferment. The alcoholic liquor is then separated for multiple distillation, leaving the solid "mash" residue.

A bulk sample of "mash" residue was obtained from Glengoyne Distillery during October 1991 by G T Cook and D D Harkness.

Pretreatment/Preparation: The bulk sample was taken from a single fermentation vat, and therefore, was already very well mixed in the industrial process. The material was immediately force-dried to avoid the possible development of mold growths and was finally subjected to physical mixing.

\subsubsection{Belfast Pine, Sample B}

Approximate age: 1 half-life

Composition/Provenance: This core sample comprises Scots pine (Pinus sylvestris), collected by Prof M Baillie in December 1991. It grew on the western side of Garry Bog, Co. Antrim, and is designated Q7780.

Each sample is a block of 40 rings, representing growth rings 74-113 of the 347-yr-old tree. The samples conform exactly to 2 of the bidecadal samples of oak used in the original high-precision calibration (Pearson and Stuiver 1986). This sample was dendro-dated to 3239-3200 BC.

Pretreatment/Preparation: The material was provided dried and split radially; no further processing was undertaken.

\subsubsection{IAEA-Cellulose, Sample C}

Activity: $129.41 \mathrm{pMC}$

Composition/Provenance: A batch of cellulose produced in 1989 from one season's harvest of about 40-yr-old trees was supplied by a paper factory in Bergum, the Netherlands.

This material is Sample C-3 in the IAEA ${ }^{14} \mathrm{C}$ quality assurance materials. The consensus value was $129.41 \mathrm{pMC}$ (with an estimated standard error of 0.06).

Pretreatment/Preparation: The material was provided already packaged and had undergone no further processing. 


\subsubsection{Hekla Peat, Sample D}

Approximate age: less than 1 half-life

Composition/Provenance: Peat was sampled at Svinavatn, North Iceland, in August 1991 with the help of Dr A Dugmore and Mr A Newton. It is associated with a tephra layer corresponding to one of the largest eruptions of the Hekla volcano.

The tephra layer corresponding to the eruption was exposed over a length of $2 \mathrm{~m}$ and a depth of approximately $1 \mathrm{~m}$ below the overlying vegetation. The tephra layer was then removed and a $1-\mathrm{cm}-$ thick layer of peat lying beneath the tephra was extracted.

Pretreatment/Preparation: The bulk peat was dried at room temperature, ground to a fine powder, and thoroughly mixed.

This material, as provided, contains about $30 \%$ by weight of carbon.

\subsubsection{Ellanmore Humic Acid, Sample E}

Approximate age: between 2 and 3 half-lives

Composition/Provenance: Details for this core sample in the series of TIRI standards are identical to those describing the optional "whole peat" standard (Sample H).

Pretreatment/Preparation: Approximately $5 \mathrm{~kg}$ of the dried bulk peat was digested in $0.25 \mathrm{M} \mathrm{KOH}$ at $80^{\circ} \mathrm{C}$. The alkali extracts were filtered and combined into one volume. The bulk aqueous solution was thoroughly mixed and the humic acids then precipitated by adjusting the solution $\mathrm{pH}$ to $<3$ by the stirred addition of $2 \mathrm{M} \mathrm{HCl}$. The solid precipitate was recovered by filtration and given a preliminary wash with cold distilled water. After drying to constant weight, the crystalline humic acid was washed free of chloride inclusions with hot distilled water.

The final product contains about $45 \%$ by weight of carbon.

\subsubsection{Icelandic Doublespar, Sample F}

Approximate age: $0 \%$ activity

Composition/Provenance: Iceland spar is a variety of crystalline calcite, its chemical composition is calcium carbonate. It occurs as pure, large, and single crystals concentrated between sheets of basic volcanic lava.

All the material used for TIRI came from the spar-mine at Helgustadir, Iceland, and was provided from the Museum of Natural History, Reykjavik, by Dr S Jakobssen.

Pretreatment/Preparation: Larger crystals provided were broken into smaller pieces and packaged in sealed bags for dispatch.

Samples from the spar-mine had been measured previously by the Radiological Dating Laboratory, NTNU, Trondheim. After removal of the outer $10 \%$, measurements showed no excess activity compared to freshly-cut marble and $\mathrm{CO}_{2}$ from natural gas. Thus, it is obvious that the crystalline structure provides excellent preservation from contamination during storage (Gulliksen and Thomsen 1992). 


\subsection{OPTIONAL SAMPLES}

\subsubsection{Fugla Ness Wood Fragments, Sample G}

Approximate age: greater than 4 half-lives

Composition/Provenance: This optional TIRI standard comprises fragments of wood (Pinus sp.) recovered from a well-documented bed of in-situ peat within glacial deposits.

The Fugla Ness section is exposed on the extreme northwest coast of Mainland Shetland, Scotland $\left(60^{\circ} 30^{\prime} \mathrm{N}, 1^{\circ} 25^{\prime} \mathrm{W}\right.$, Natl Grid Ref HU 311913$)$. The stratigraphy was first described by Chapelhow (1965) as a $1.5-\mathrm{m}$ band of amorphous peat buried beneath 2 tills. On the basis of its pollen and rich macrofossil content, Birks and Ransom (1969) concluded that the peat layer was of interglacial age and with strong Gortian (cf. Hoxnian) affinities. A critical re-evaluation of the pollen-stratigraphic evidence is provided by Lowe (1984).

A bulk sample of wood fragments was collected by fresh excavation of the section during August 1991 by A M Hall, D D Harkness, G Whittington, and N J Alexander.

Pretreatment/Preparation: The wood fragments had been subjected to a preliminary cleaning to discard adhering peat and other soluble organic residues.

The raw sample was soaked in distilled water for several days, digested in $0.5 \mathrm{M} \mathrm{KOH}$ at $80{ }^{\circ} \mathrm{C}$, and then re-soaked in fresh distilled water. Individual fragments were then scrubbed using a wire brush and digested overnight in hot $2 \mathrm{M} \mathrm{HCl}$. The wood was again soaked in several washes of distilled water to remove excess acid, and then dried to constant weight in a vacuum oven.

Further decontamination by either acid/alkali/acid digestion and/or extraction of the component cellulose is strongly recommended prior to any attempt to date this natural material.

\subsubsection{Ellanmore Whole Peat, Sample H}

Approximate age: between 2 and 3 half-lives

Composition/Provenance: This optional TIRI standard is finely-ground peat from a well-defined stratigraphic section. The Ellanmore peat occurs as an approximately 50 -cm-thick horizon intercalated with glacial diamicts and is exposed in a stream bank section of the Reisgill Burn, Ellanmore, Caithness, Scotland ( $58^{\circ} 18^{\prime} \mathrm{N}, 3^{\circ} 17^{\prime} \mathrm{W}$, Natl Grid Ref ND 237370$)$. The stratigraphical section is described and discussed in detail by Hall and Whittington (1981).

During September 1991, a bulk sample comprising about $10 \mathrm{~kg}$ of peat was cut from a freshly cleaned exposure by A M Hall and D D Harkness.

Pretreatment/Preparation: The bulk peat was air-dried at room temperature. Approximately half of the available material was ground to a fine powder and thoroughly mixed to produce an age homogeneous standard.

This material, as provided, contains about $40 \%$ by weight of carbon.

\subsubsection{Caerwys Quarry Travertine, Sample I}

Approximate age: within 1 and 2 half-lives

Composition/Provenance: This optional TIRI standard was available for distribution to those laboratories that had an interest in dating freshwater travertines (tufas) of postglacial origin. 
A bulk sample of fresh material $\left(98 \% \mathrm{Ca} \mathrm{CO}_{3}\right)$ was collected from a well-documented exposure at Caerwys Quarry, North Wales (Natl Grid Ref 33 129 719), during April/May 1992.

\subsubsection{Buiston Crannog Wood, Sample J}

Approximate age: less than 1 half-life

Composition/Provenance: This timber, available as an optional TIRI standard, was in the form of a large morticed baulk, lying just behind the outer palisade of Buiston Crannog, near Kilmaurs, Ayrshire, Scotland $\left(55^{\circ} 40^{\prime} \mathrm{N}, 4^{\circ} 18^{\prime} \mathrm{W}\right.$, NGR 41544351$)$. Although no longer in situ, it resembled the morticed planks used to secure the stakes of the outer palisade and is interpreted here as having formed part of the latter. The sample was supplied by Dr B A Crone, Archaeological Operations and Conservation, Fleming House, Newcraighall, Edinburgh.

Pretreatment/Preparation: The samples were cut from a single timber. No chemical treatment had been undertaken.

\subsubsection{Turbidite Carbonate (Mainly Coccolith Calcite), Sample K}

Approximate age: 3 half-lives

Composition/Provenance: This optional TIRI standard is from a single, distal turbidite emplaced on the Madeira Abyssal Plain, east of Great Meteor Seamount, a few hundred years ago. A remarkable feature of these turbidites is their homogeneity. The basal layers are graded and inhomogeneous, but are overlain by relatively thick, ungraded deposits. These are further overlain by surficial (approximately a 10-cm layer) material which is, again, non-homogeneous. The material used in this study is derived from the middle ungraded deposit. The sample was supplied by Dr J Thomson, Institute of Oceanographic Sciences, Deacon Laboratory, Wormley, England.

Pretreatment/Preparation: On receipt, the sample was immediately oven-dried $\left(\sim 50^{\circ} \mathrm{C}\right)$, ground, and fully homogenized.

\subsubsection{Whalebone, Sample L}

Approximate age: between 2 and 3 half-lives

Composition/Provenance: This optional TIRI standard comprises sections of whalebone recovered from a complete whale skeleton discovered in Flatanger, Norway. The skeleton has been buried under approximately $2 \mathrm{~m}$ of Quaternary till and beach gravel.

The whole skeleton was freshly excavated in March 1992 by Sigmund Alsaker in collaboration with the Geological Survey of Norway (NGU) and the Radiological Dating Laboratory in Trondheim.

The further financial support of the municipality of Flatanger is gratefully acknowledged.

\subsubsection{Icelandic Peat, Sample M}

Approximate age: less than 1 half-life

Composition/Provenance: This optional TIRI standard comprises peat sampled in August 1991 from Solheimajokull, South Iceland, with the help of Dr A Dugmore and Mr A Newton.

The peat sample was taken from a thin section between 2 tephra layers, at approximately $1 \mathrm{~m}$ below the underlying vegetation layer.

Pretreatment/Preparation: The whole peat was dried and ground to a fine powder, then thoroughly mixed. This material, as provided, contains approximately $10 \%$ by weight of carbon. 


\section{RESULTS FOR STAGE 1: CORE SAMPLES}

\subsection{PARTICIPATING LABORATORIES}

A total of 93 sets of samples were dispatched and 67 sets of results were received. A number of laboratories submitted more than 1 set of results, the additional sets of results typically having been produced as a result of collaboration with an accelerator laboratory (target preparation in 1 laboratory, measurement in another). In total, 42 sets of results were produced using liquid scintillation technology (LSC), including 1 by direct $\mathrm{CO}_{2}$ absorption (CARB), 18 by gas proportional counting (GPC), and 11 by accelerator mass spectrometry (AMS). The list of participating laboratories is shown in Table 3.1 and the full results are given in Appendix 4.

Table 3.1 Laboratories participating in TIRI

\begin{tabular}{|c|c|c|}
\hline Laboratory name & Country & Laboratory type \\
\hline INRA, Science du Sol & France & LSC \\
\hline RAWS, Heidelberg & Germany & GPC \\
\hline Datación por Carbono-14 & Spain & LSC \\
\hline Svedberg Lab, Uppsala University & Sweden & AMS \\
\hline Rafter Lab, Nuclear Science & New Zealand & AMS \\
\hline Physical Research Lab & India & GPC \\
\hline Physical Research Lab & India & LSC \\
\hline NLB, Radiocarbon Lab & Germany & GPC \\
\hline LOYDC, Paris & France & LSC \\
\hline Dating Lab, University of Helsinki & Finland & GPC \\
\hline Radiocarbon Dating & England & LSC \\
\hline INAN, University of Louvain & Belgium & GPC \\
\hline National Museum & Denmark & GPC \\
\hline Weizmann Institute & Israel & GPC \\
\hline Institute of Material Culture & Russia & LSC \\
\hline Institute of Geography & China & LSC \\
\hline MWG MacIntosh Centre & Australia & LSC \\
\hline University of California & USA & GPC \\
\hline University of Texas & USA & LSC \\
\hline SUERC & Scotland & LSC \\
\hline Geologie du Quaternaire & France & LSC \\
\hline ATOMKI & Hungary & GPC \\
\hline University of Rome & Italy & GPC \\
\hline AMS lab, Aarhus & Denmark & AMS \\
\hline CAMS/LLNL & USA & AMS \\
\hline Techniques Nucleaire & Algeria & $\mathrm{LSC}$ \\
\hline Van de Graaf Lab & Netherlands & AMS \\
\hline Institute of Zoology and Botany & Estonia & LSC \\
\hline Saskatchewan Research Council & Canada & LSC \\
\hline Research Lab for Archaeology & England & AMS \\
\hline Centre de Datation & France & LSC \\
\hline Belfast & Ireland & LSC \\
\hline Kyoto Sangyo University & Japan & LSC \\
\hline Tallinn ${ }^{14} \mathrm{C} \mathrm{Lab}$ & Estonia & LSC \\
\hline Kraków & Poland & LSC \\
\hline Illinois Geological Survey & USA & LSC \\
\hline Ruđer Bošković Institute & Croatia & GPC \\
\hline
\end{tabular}


Table 3.1 Laboratories participating in TIRI (Continued)

\begin{tabular}{lll}
\hline Laboratory name & Country & Laboratory type \\
\hline ICEN/LNETI & Portugal & LSC \\
National Taiwan University & Taiwan & LSC \\
LATYR & Argentina & LSC \\
Bhabha Atomic Research & India & LSC \\
CRAD & Italy & LSC \\
UFZ & Germany & LSC \\
Institut für Radiumforschung & Austria & GPC \\
Department of Geography & Wales & GPC \\
Japan Radiosiotope & Japan & GPC \\
Geographical Institute & Russia & LSC \\
Atomic Energy for peace & Thailand & LSC \\
Palaeoclimatologie im WIP & Germany & LSC \\
CSIRO & Australia & CARB \\
Department of Geosciences & USA & LSC \\
Scienze della Terra & Italy & LSC \\
Institut für Kernphysik & Germany & GPC \\
Bergakademie & Germany & LSC \\
WHOI & USA & AMS \\
DAI & Germany & GPC \\
University of Rome & Italy & LSC \\
NERC ${ }^{4}$ C Lab & Scotland & LSC \\
Radiologisk Datering & Norway & GPC \\
Beta Analytic & USA & LSC/AMS \\
WHOI & USA & GPC \\
British Museum & England & LSC \\
SMU & USA & LSC \\
Radiologisk Datering & Norway & AMS \\
University of Barcelona & Spain & LSC \\
NSF-Arizona AMS & USA & AMS \\
University of Waikato & New Zealand & LSC \\
Geological Survey of Canada & Canada & GPC \\
\hline
\end{tabular}

\subsection{SUMMARY STATISTICS}

The summary statistics for each sample are presented below and follow a common pattern:

a) Boxplots for $\delta^{14} \mathrm{C}, \Delta^{14} \mathrm{C}$, and \%Modern (pMC) or age, are shown. Such diagrams show the overall distribution of results, indicating (by the central box) the middle $50 \%$ of the data (the interquartile range, IQR), the extremes (minimum and maximum), and any outlying observations (indicated by * and 0 on the diagrams).

b) A numerical summary of the results is given in an accompanying table. $N$ indicates the number of observations. The mean and median give estimates of the central value (used as the consensus) and the quartiles Q1 and Q3 give the range within which the mid-50\% of the data lie.

c) The presentation of the results by laboratories was quite varied; sometimes only age was reported, on other occasions $\delta^{14} \mathrm{C}, \Delta{ }^{14} \mathrm{C}$, and age were given. In the summary tables, we have based the calculations on all the results for a particular quantity, including results on different sub-samples of the same sample. Thus, in some of the tables, the number of results being summarized exceed the number of laboratories that participated. 
For Sample F, we have provided several tables since there was an additional complication that results were often censored (reported in the form of a "greater than" age).

\subsubsection{Statistical Summary for TIRI-A: Glengoyne Barley Mash}

Figure 3.1 Distribution of results for Barley mash TIRI-A

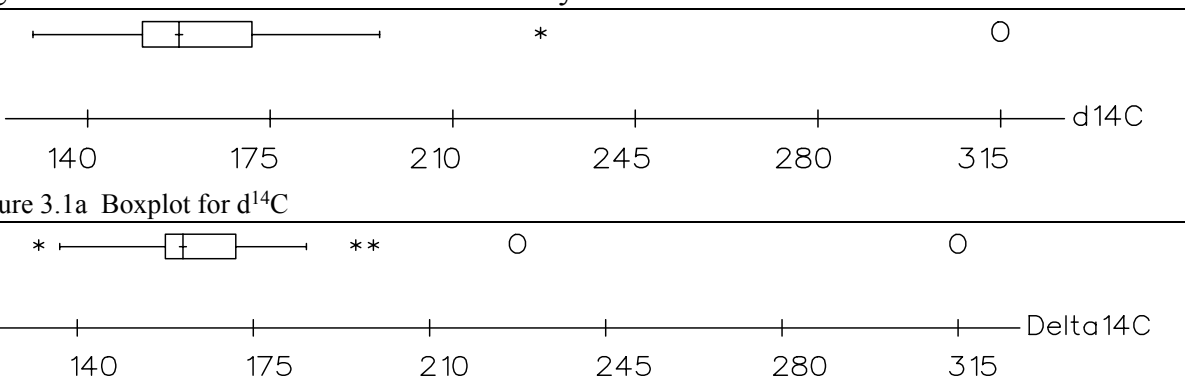

Figure 3.1b Boxplot for $\mathrm{D}^{14} \mathrm{C}$

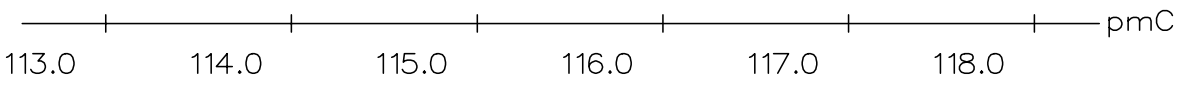

Figure 3.1c Boxplot for pMC

Table 3.2 Numerical summary for TIRI-A

\begin{tabular}{llllll}
\hline & $\mathrm{N}$ & Mean & Median & $\mathrm{Q} 1$ & $\mathrm{Q} 3$ \\
\hline $\mathrm{d}^{14} \mathrm{C}$ & 50 & 165.06 & 160.18 & 151.80 & 171.57 \\
$\mathrm{D}^{14} \mathrm{C}$ & 62 & 167.91 & 164.14 & 157.88 & 172.20 \\
$\mathrm{pMC}$ & 25 & 116.12 & 116.35 & 115.30 & 117.08 \\
\hline
\end{tabular}

Comments: The mean activity is $116.12 \mathrm{pMC}$, with an interquartile range of 1.78 .

\subsubsection{Statistical Summary of Results for TIRI-B: Belfast Pine}

Figure 3.2 Distribution of results for Belfast pine TIRI-B

\begin{tabular}{|c|c|c|c|c|c|}
\hline$\infty$ & & * & +5 & * & O \\
\hline-510 & -480 & -450 & -420 & -390 & -360 \\
\hline \multicolumn{6}{|c|}{ Figure 3.2a Boxplot for $\mathrm{d}^{14} \mathrm{C}$} \\
\hline \multicolumn{2}{|l|}{0} & * & $\longrightarrow$ & 00 & \multirow{2}{*}{ - delta14C } \\
\hline-510 & -480 & -450 & -420 & -390 & \\
\hline \multicolumn{6}{|c|}{ Figure $3.2 \mathrm{~b}$ Boxplot for $\mathrm{D}^{14} \mathrm{C}$} \\
\hline 0 & $0 \quad 0$ & $-t$ & k** & & O \\
\hline \multicolumn{6}{|c|}{$\begin{array}{llll}1 & 1 & 1 & 1 \\
7000 & \text { age(BP) }\end{array}$} \\
\hline 3600 & 4000 & 4400 & 4800 & 5200 & 5600 \\
\hline \multicolumn{6}{|c|}{ Figure 3.2c Boxplot for age (yr BP) } \\
\hline
\end{tabular}


Table 3.3 Numerical summary for TIRI-B

\begin{tabular}{llllll}
\hline & $\mathrm{N}$ & Mean & Median & Q1 & Q3 \\
\hline $\mathrm{d}^{14} \mathrm{C}$ & 47 & -428.52 & -427.30 & -434.17 & -421.79 \\
$\mathrm{D}^{14} \mathrm{C}$ & 63 & -426.93 & -428.96 & -434.40 & -423.10 \\
Age & 78 & 4485 & 4500 & 4420 & 4540 \\
\hline
\end{tabular}

Comments: The mean ${ }^{14} \mathrm{C}$ age is 4485 BP (the "expected" age from the dendro-dates is approximately $4495 \mathrm{BP})$. The IQR is $140 \mathrm{yr}$.

\subsubsection{Statistical Summary for TIRI-C: IAEA-Cellulose}

Figure 3.3 Boxplots for TIRI-C: IAEA-cellulose

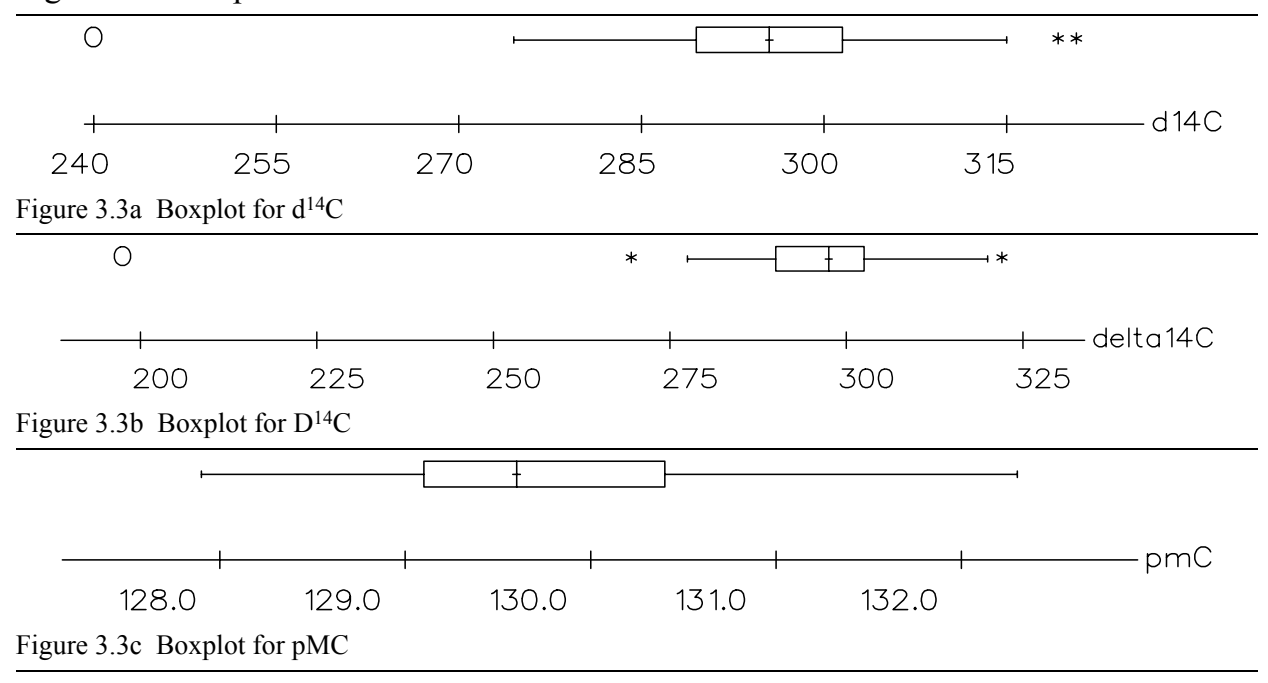

Table 3.4 Numerical summary for TIRI-C

\begin{tabular}{llllll}
\hline & $\mathrm{N}$ & Mean & Median & Q1 & Q3 \\
\hline $\mathrm{d}^{14} \mathrm{C}$ & 45 & 295.42 & 295.50 & 290.2 & 302.1 \\
$\mathrm{D}^{14} \mathrm{C}$ & 58 & 295.98 & 297.35 & 291.3 & 303.6 \\
$\mathrm{pMC}$ & 25 & 129.81 & 129.60 & 129.1 & 130.5 \\
\hline
\end{tabular}

Comments: The mean activity is 129.81 pMC, compared with the IAEA reference value of 129.41 . The IQR is 1.4. 


\subsubsection{Statistical Summary of TIRI D: Hekla Peat}

Figure 3.4 Distribution of results TIRI D: Hekla peat

\begin{tabular}{|c|c|c|c|c|c|}
\hline$*$ & $\longmapsto$ & $\square$ & $\longrightarrow$ & * & * \\
\hline-405 & -390 & -375 & -360 & -345 & -330 \\
\hline \multicolumn{6}{|c|}{ Figure 3.4a Boxplot for $\mathrm{d}^{14} \mathrm{C}$} \\
\hline $\mathrm{O}$ & $\longmapsto$ & + & 乙** & & $\mathrm{O}$ \\
\hline-405 & -390 & -375 & -360 & -345 & -330 \\
\hline \multicolumn{6}{|c|}{ Figure $3.4 \mathrm{~b}$ Boxplot for $\mathrm{D}^{14} \mathrm{C}$} \\
\hline $\mathrm{O}$ & & $* *$ & $t$ & $* *$ & 0 \\
\hline 3200 & 3400 & 3600 & 3800 & 4000 & 4200 \\
\hline
\end{tabular}

Figure 3.4c Boxplot for age (yr BP)

Table 3.5 Numerical summary for TIRI-D

\begin{tabular}{llllll}
\hline & $\mathrm{N}$ & Mean & Median & $\mathrm{Q} 1$ & $\mathrm{Q} 3$ \\
\hline $\mathrm{d}^{14} \mathrm{C}$ & 46 & -379.25 & -381.25 & -386.4 & -373.6 \\
$\mathrm{D}^{14} \mathrm{C}$ & 60 & -376.25 & -377.25 & -380.9 & -372.6 \\
Age $(\mathrm{BP})$ & 72 & 3799 & 3805 & 3752 & 3865 \\
\hline
\end{tabular}

Comments: The mean is 3799 yr BP, with an IQR of 113 yr BP. A number of outliers are identified.

\subsubsection{Statistical Summary for TIRI E: Ellanmore Humic}

Figure 3.5 Statistical summary for TIRI E: Ellanmore humic

\begin{tabular}{cccccc}
\hline & & & $*$ & & 0 \\
\hline-780 & -760 & -740 & -720 & -700 & -680
\end{tabular}

Figure 3.5a Boxplot for $\mathrm{d}^{14} \mathrm{C}$

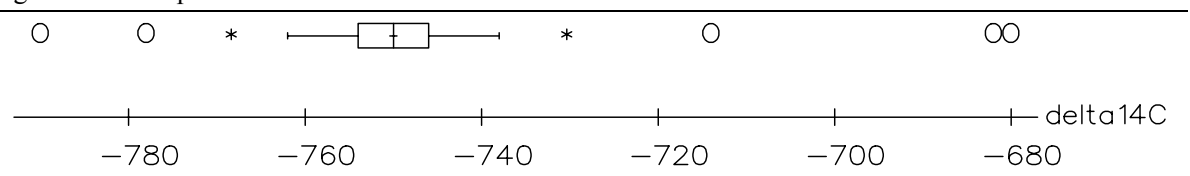

Figure $3.5 \mathrm{~b}$ Boxplot for $\mathrm{D}^{14} \mathrm{C}$

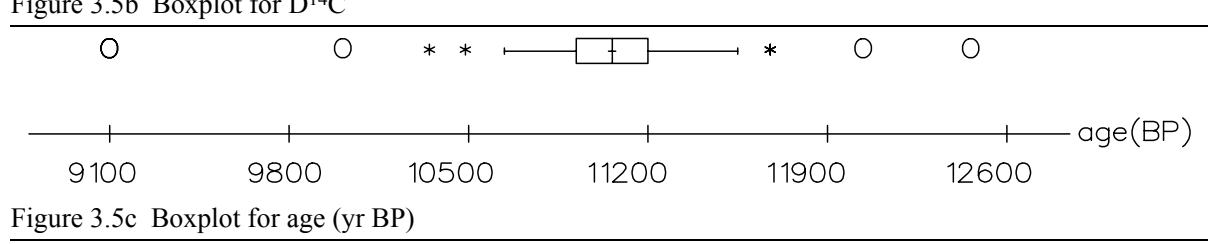


Table 3.6 Numerical summary for TIRI-E

\begin{tabular}{llcccc}
\hline & $\mathrm{N}$ & Mean & Median & $\mathrm{Q} 1$ & $\mathrm{Q} 3$ \\
\hline $\mathrm{d}^{14} \mathrm{C}$ & 43 & -747.7 & -749.5 & -755.5 & -743.0 \\
$\mathrm{D}^{14} \mathrm{C}$ & 56 & -747.0 & -748.6 & -752.2 & -745.2 \\
Age (BP) & 68 & 11,066 & 11,105 & 10,965 & 11,240 \\
\hline
\end{tabular}

Comments: The mean age is $11,066 \mathrm{yr} \mathrm{BP}$, with an IQR of $175 \mathrm{yr}$. A number of outliers are apparent.

\subsubsection{Statistical Summary for TIRI F: Icelandic Doublespar}

Figure 3.6 Distribution of results for TIRI F: Icelandic doublespar

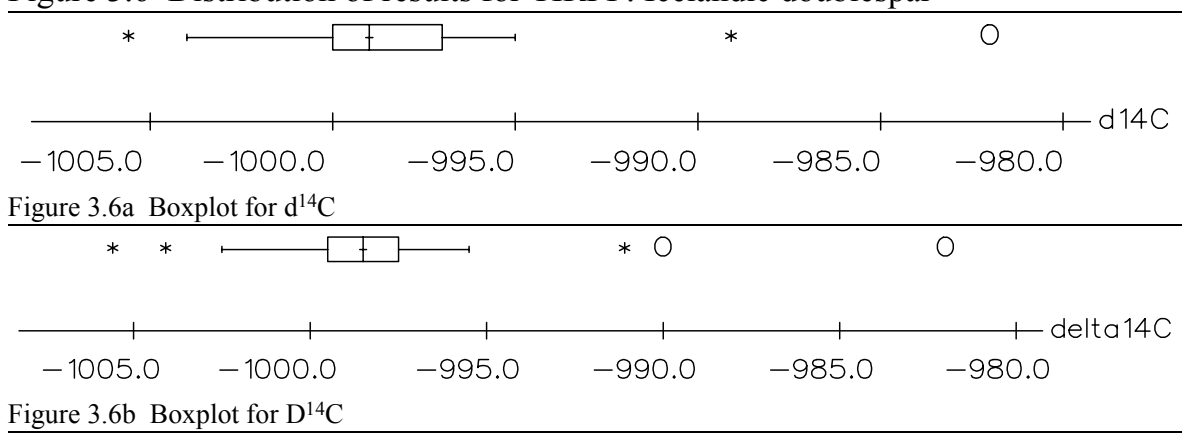

Table 3.7 Numerical summary for TIRI-F

\begin{tabular}{llllll}
\hline & $\mathrm{N}$ & Mean & Median & Q1 & Q3 \\
\hline $\mathrm{d}^{14} \mathrm{C}$ & 33 & -997.9 & -998.6 & -1000.0 & -996.6 \\
$\mathrm{D}^{14} \mathrm{C}$ & 51 & -997.9 & -998.2 & -999.5 & -997.0 \\
\hline
\end{tabular}

Comments: For this sample, 21 results were simply classified as "background" and 19 results were given in the form of a finite age. These results are summarized below:

\begin{tabular}{lllll} 
& Mean & Median & Q1 & Q3 \\
\hline Age (BP) & 48,198 & 49,030 & 44,160 & 52,106 \\
\hline
\end{tabular}

Twenty-two results were given in the form of $>$ age (BP). The ages are summarized below:

\begin{tabular}{lllll} 
& Mean & Median & Q1 & Q3 \\
\hline$>$ Age $(\mathrm{BP})$ & 46,076 & 46,150 & 39,450 & 53,400 \\
\hline
\end{tabular}

\subsection{PRELIMINARY CONCLUSIONS}

1. For the 2 modern samples, $\mathrm{A}$ and $\mathrm{C}$, we found that a number of laboratories calculated a slightly different form for pMC (by incorporating an allowance for decay). To ensure that all results are directly comparable, we asked labs to confirm their results without decay correction.

2. For Sample A, it is clear that there are a number of outlying observations. The preliminary consensus value is $116.35 \mathrm{pMC}$.

3. For Samples B, D, and E, there are no obvious computational problems. A few outlying observations are apparent. Consensus values are $4500 \mathrm{BP}, 3805 \mathrm{BP}$, and 11,105 BP, 
respectively. For Sample B, the known-age sample, the known ${ }^{14} \mathrm{C}$ age is $4495 \mathrm{BP}$, so the results are in good agreement.

4. For Sample C, a few outlying observations are apparent. The consensus value is 129.6 , which is slightly higher than the IAEA value of 129.4.

5. For Sample F, the results have proved particularly interesting. This material was selected to function as a background sample. A relatively large number of laboratories reported a finite age for this sample, indicating a statistically significant ${ }^{14} \mathrm{C}$ count rate relative to their accepted background.

Other laboratories simply stated that the sample was background, while others gave their result in the form of >age (BP). Generally speaking, the consensus value would indicate an age greater than $46,150 \mathrm{yr}$ BP.

6. Given the diversity of form of results for this sample, perhaps there is a need for careful consideration of the limiting age calculations. For almost all samples, outliers or extreme values have been graphically identified.

\subsection{CONSENSUS VALUES}

Consensus values for each sample were evaluated using the same method used in the characterization of the IAEA reference samples (Rozanski et al. 1992). Briefly, a preliminary robust consensus value ( $\mathrm{rcv}$ ) was evaluated (the median of all the results with identified outliers removed) for each of the samples. To evaluate the final consensus value, the standardized difference (sd) between the robust consensus value (rcv) and each result is calculated (sd = [result-rcv] / quoted error). If the standardized difference exceeds 2 , then that result is not used in any subsequent calculation. In this way, results that do not lie within \pm 2 quoted errors of the robust consensus value are removed. The final consensus value is calculated as a weighted average of the remaining results.

The following tables show the consensus values for the core samples, evaluated using the criterion stated above.

Table 3.8 Consensus values for core samples

\begin{tabular}{lcc}
\hline Sample & Consensus value & Estimated precision $(1 \sigma)$ \\
\hline A: barley mash & $116.35 \mathrm{pMC}$ & 0.0084 \\
B: Belfast pine & $4503 \mathrm{BP}$ & 6 \\
C: IAEA cellulose & $129.7 \mathrm{pMC}$ & 0.08 \\
D: Hekla peat & $3810 \mathrm{BP}$ & 7 \\
E: Ellanmore humic & $11,129 \mathrm{BP}$ & 12 \\
F: Icelandic doublespar $(\mathrm{BP})$ & $46,750 \mathrm{BP}$ & 208 \\
F: Icelandic doublespar $(\mathrm{pMC})$ & $0.18 \mathrm{pMC}$ & 0.006 \\
\hline
\end{tabular}

For each sample, a number of outliers were removed (up to a maximum of 10, but more typically less than 5). When the consensus value was calculated, results were also omitted due to the $\pm 2 \sigma$ criterion not being satisfied.

The results are presented graphically in Figures 3.7-3.13, where plots for each core sample show the results for the individual laboratories and their differences from the consensus values. The vertical bars represent \pm 2 quoted uncertainties. Where a laboratory has not quoted an uncertainty (e.g., for Sample F), the result is shown without bars. We would expect that the results should be scattered around zero and this is the case. The figures also show the variation in the quoted errors among laboratories. 


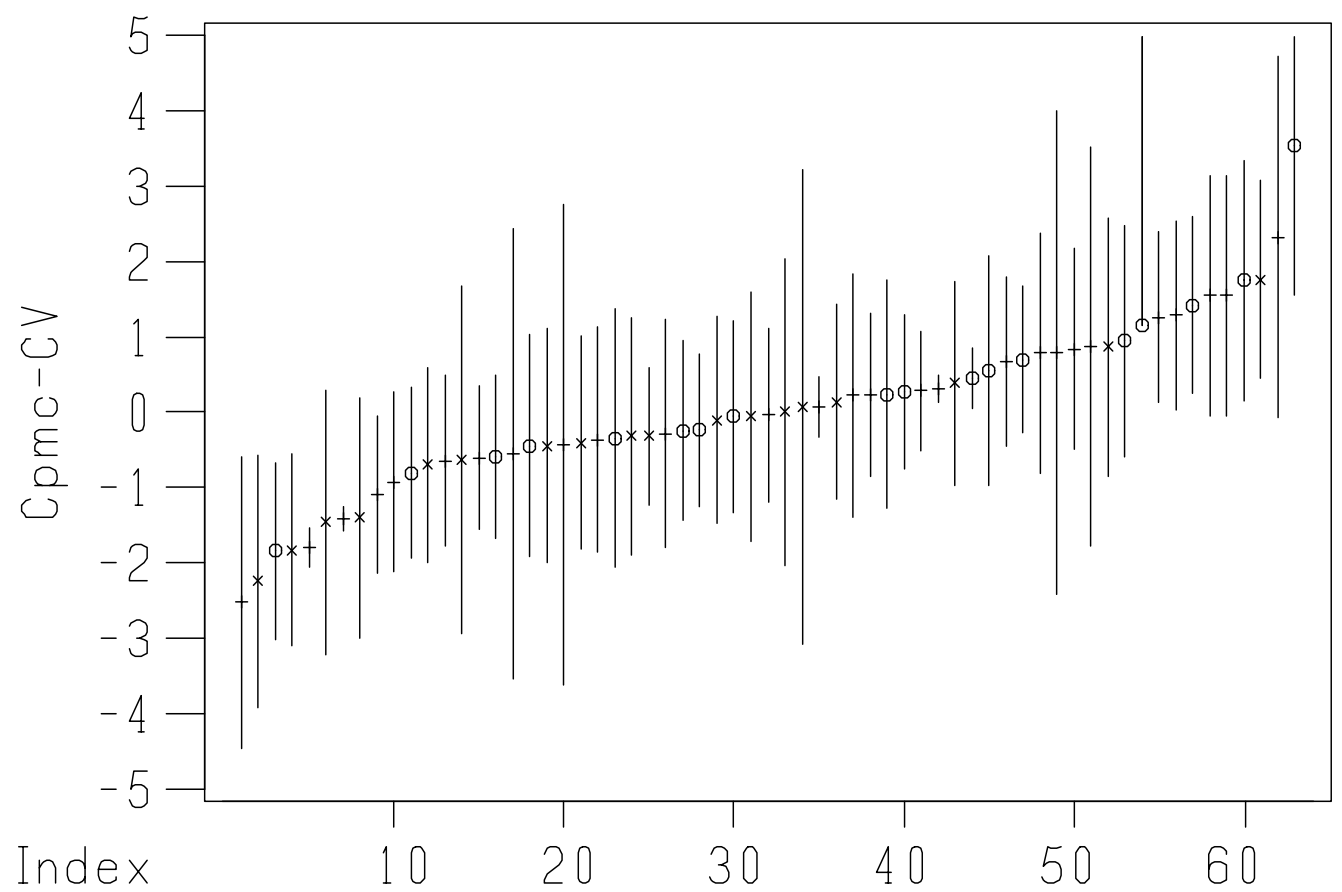

Figure 3.7 Sample A: Glengoyne barley mash

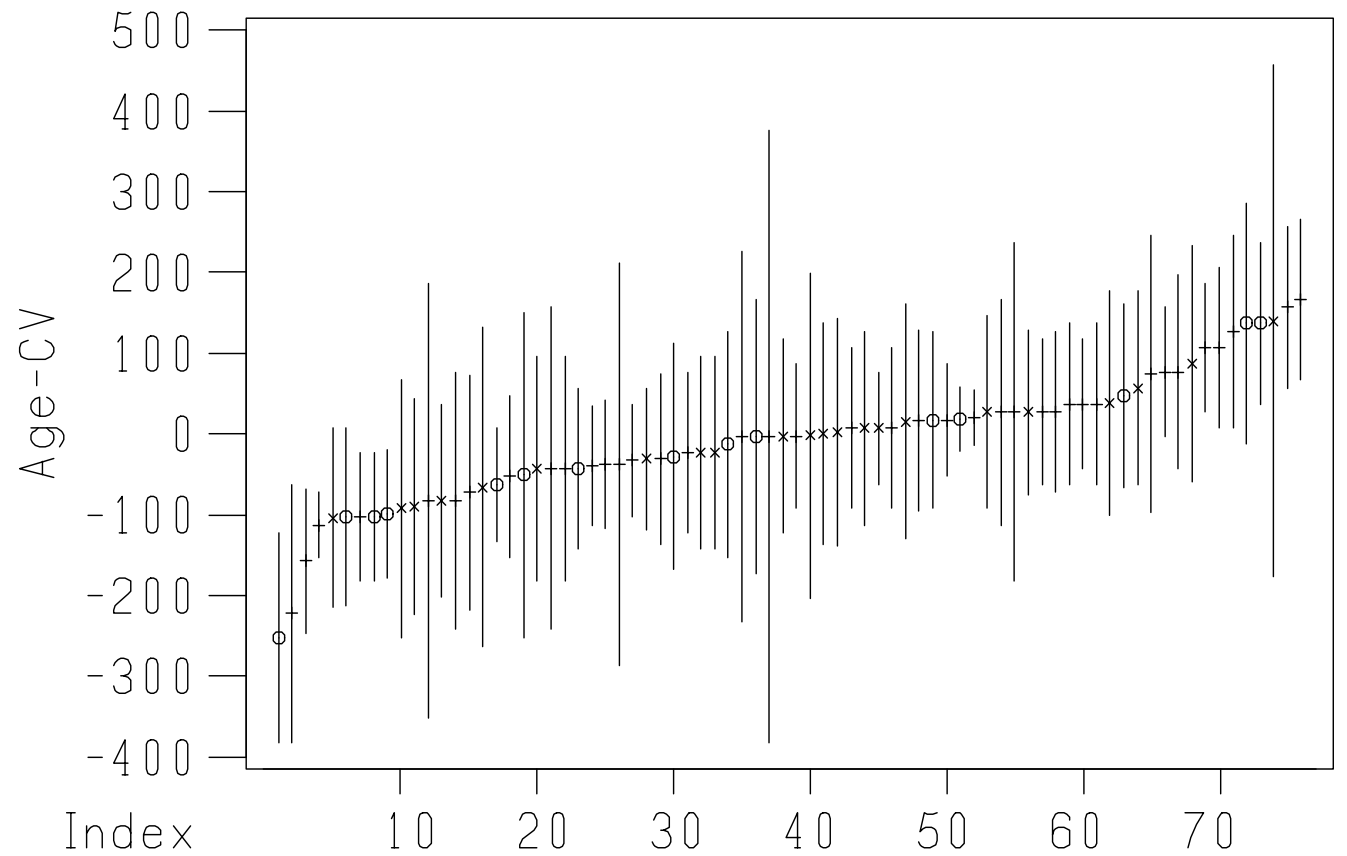

Figure 3.8 Sample B: Belfast wood 


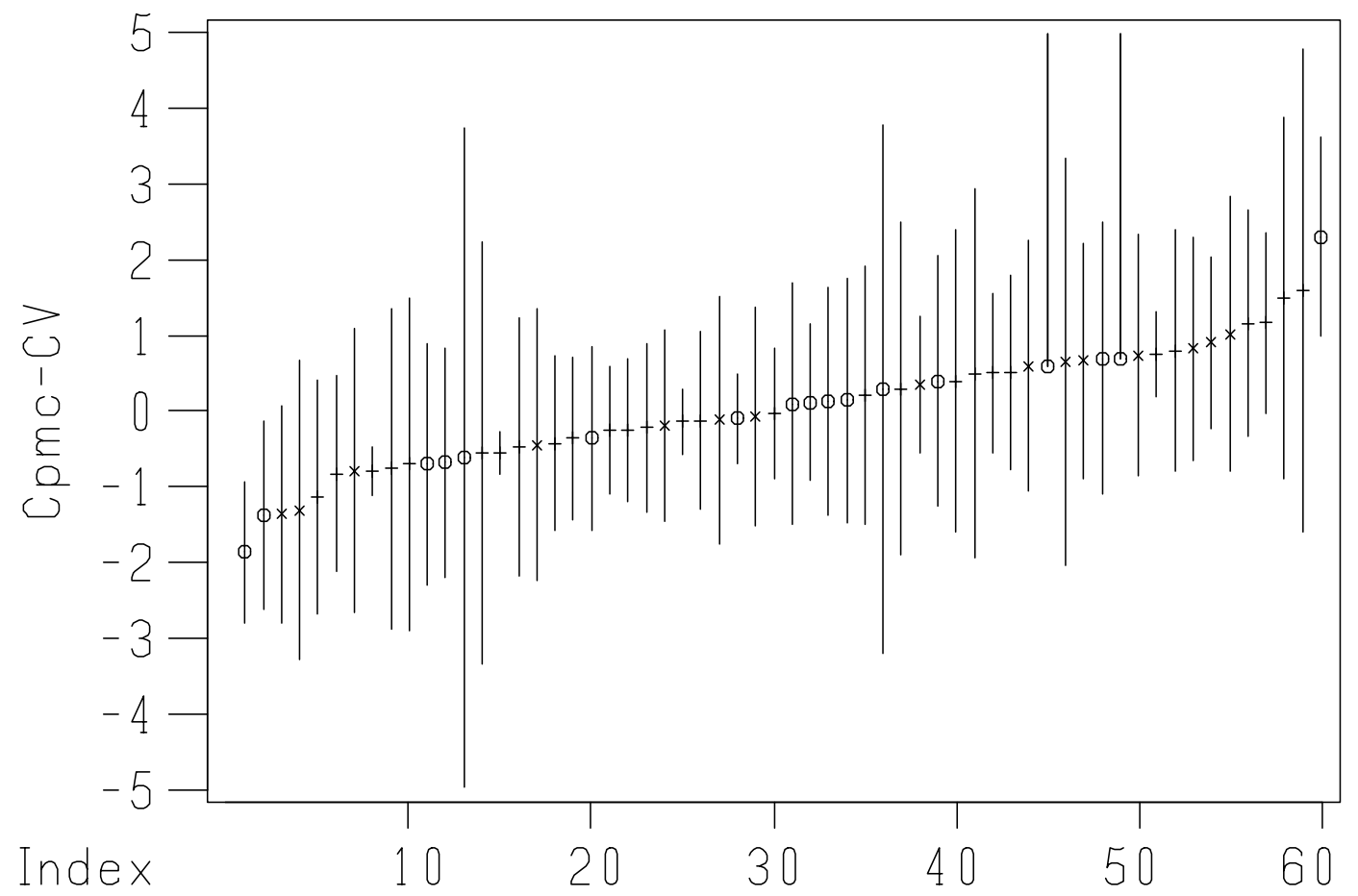

Figure 3.9 Sample C: IAEA cellulose

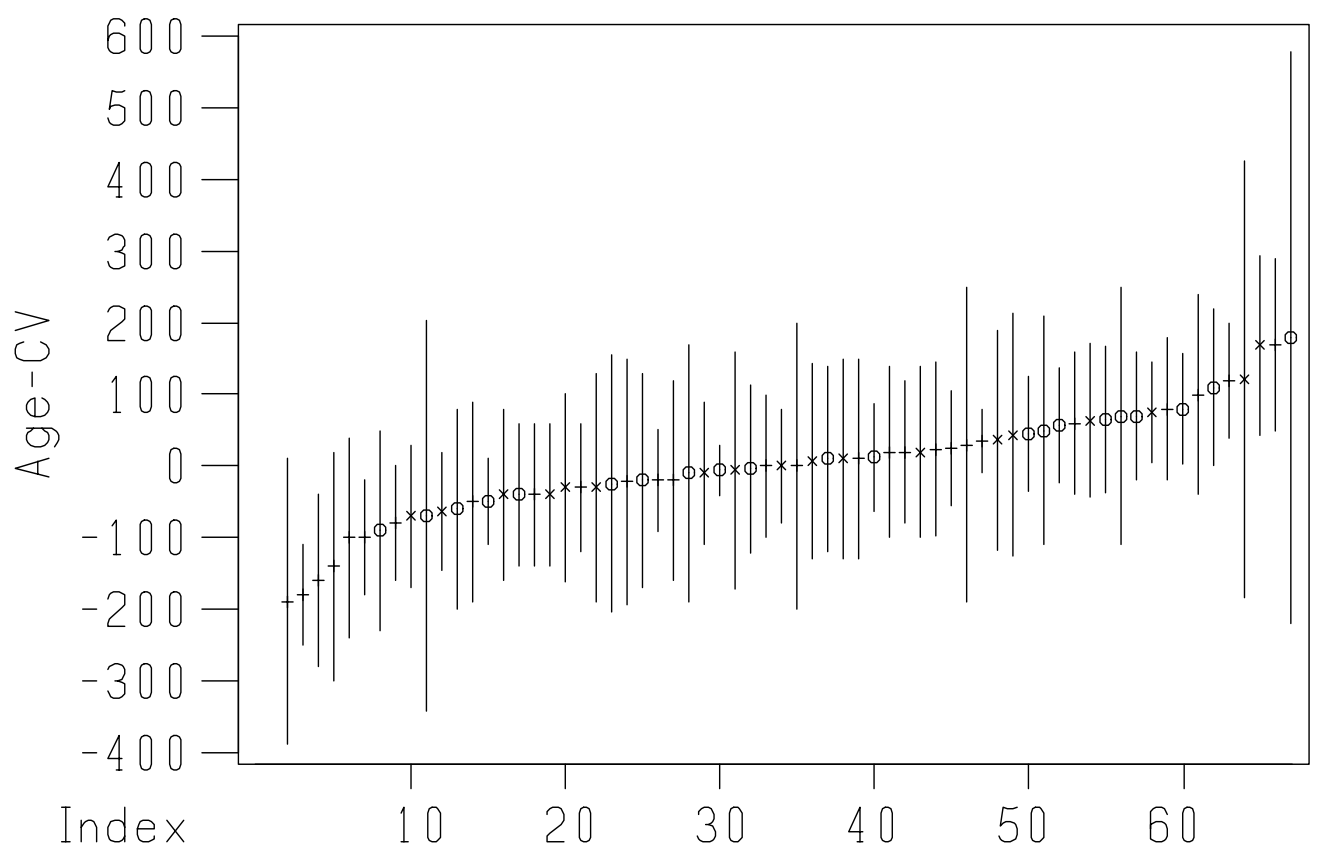

Figure 3.10 Sample D: Hekla peat 


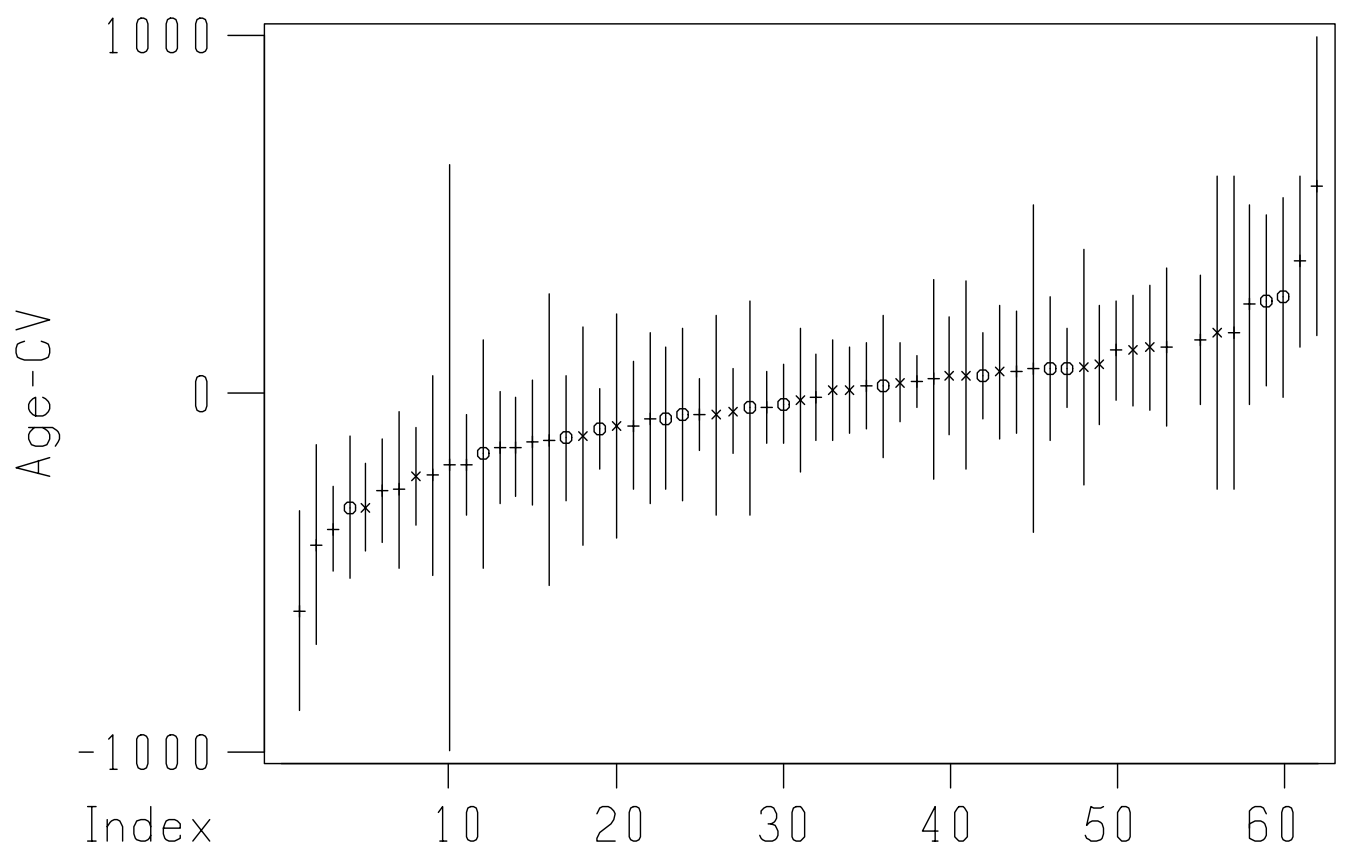

Figure 3.11 Sample E: Ellanmore humic

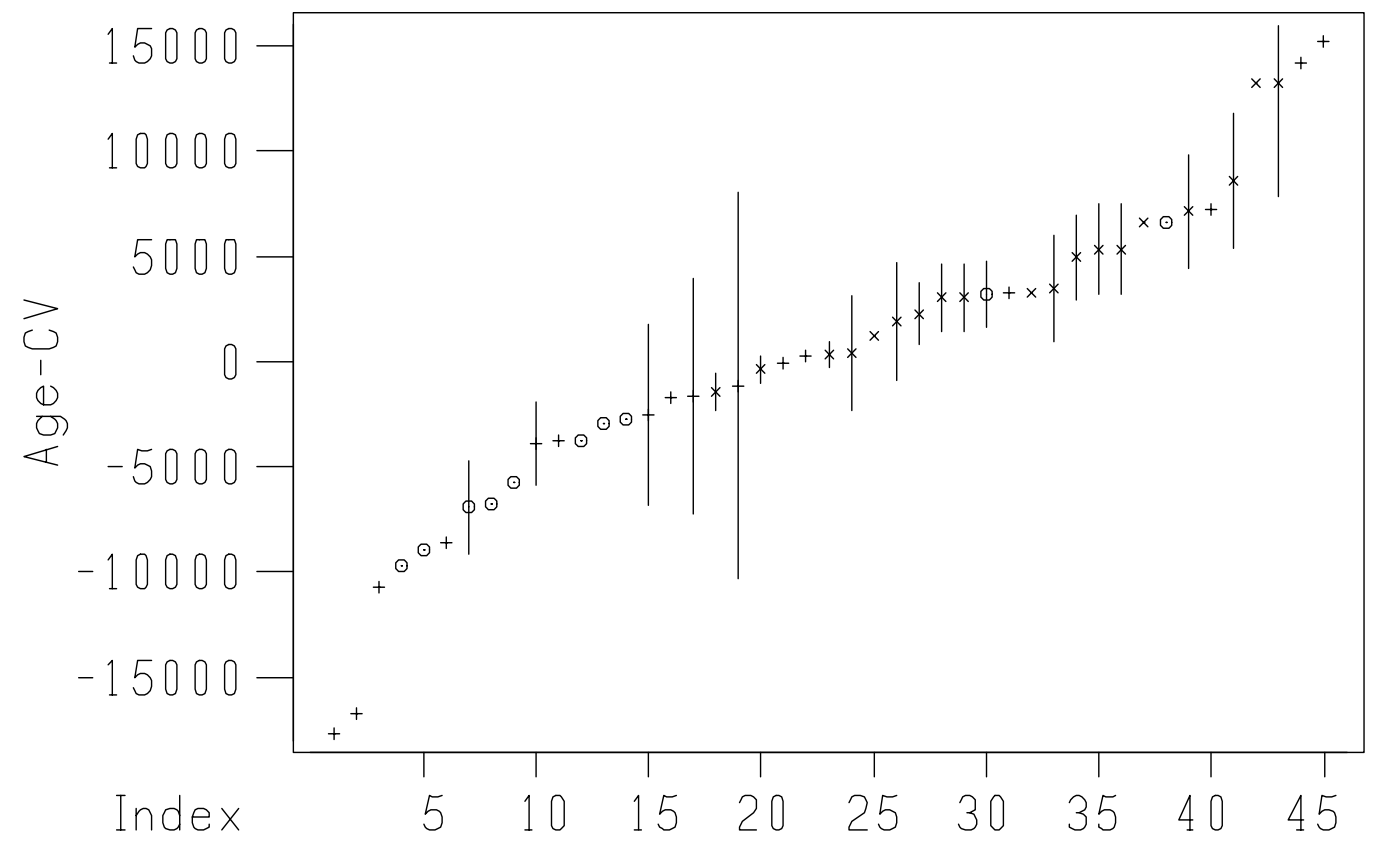

Figure 3.12 Sample F: Icelandic doublespar (yr BP) 


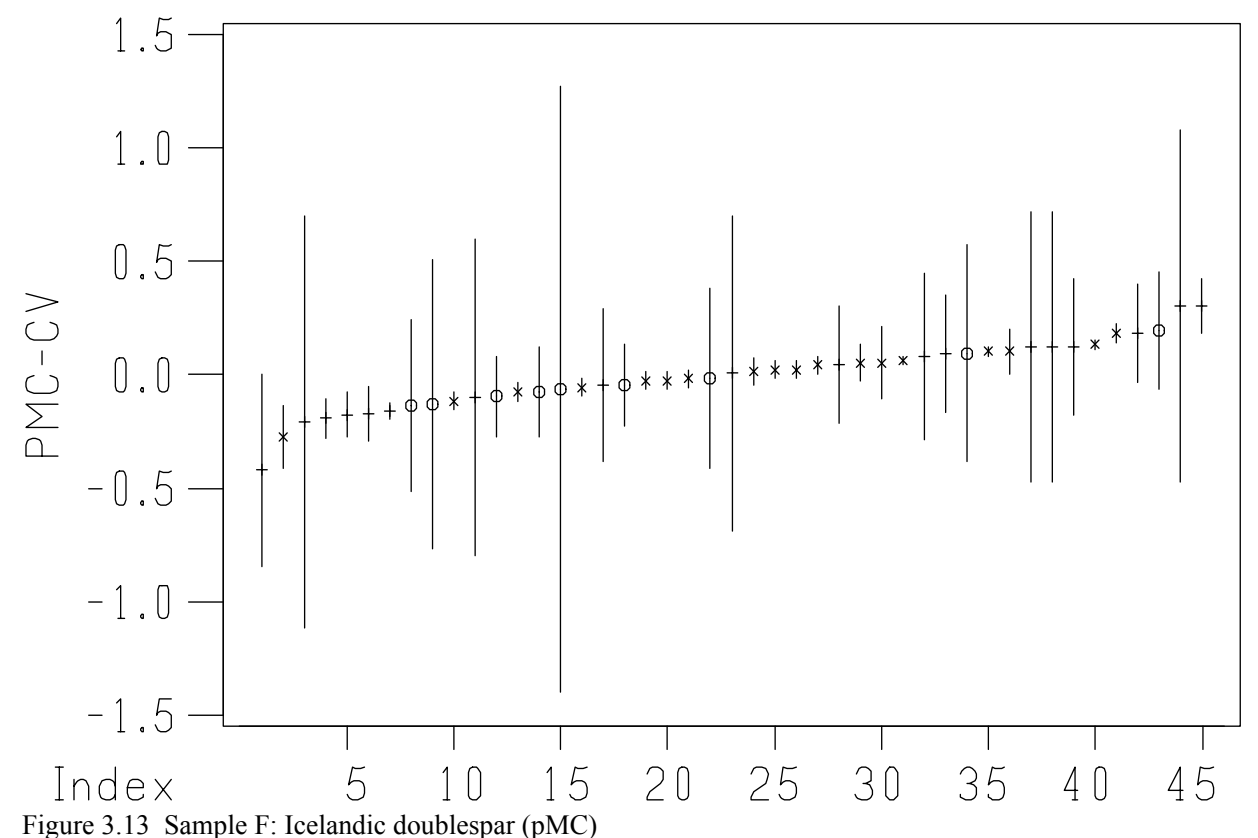

Further, to allow a comparison of the scatter of results for the different samples, deviations have been calculated, where the deviation is defined as:

Deviation $=($ laboratory result - consensus value $) /$ quoted uncertainty

We would anticipate that deviations should generally lie between \pm 2 , (normal counting statistics). Figures 3.14-3.19 show the deviations for the 6 core samples for LSC, GPC, and AMS labs. In the main, the results are very tight, but we do see some evidence of wider scatter in Sample F for LSC and AMS labs.

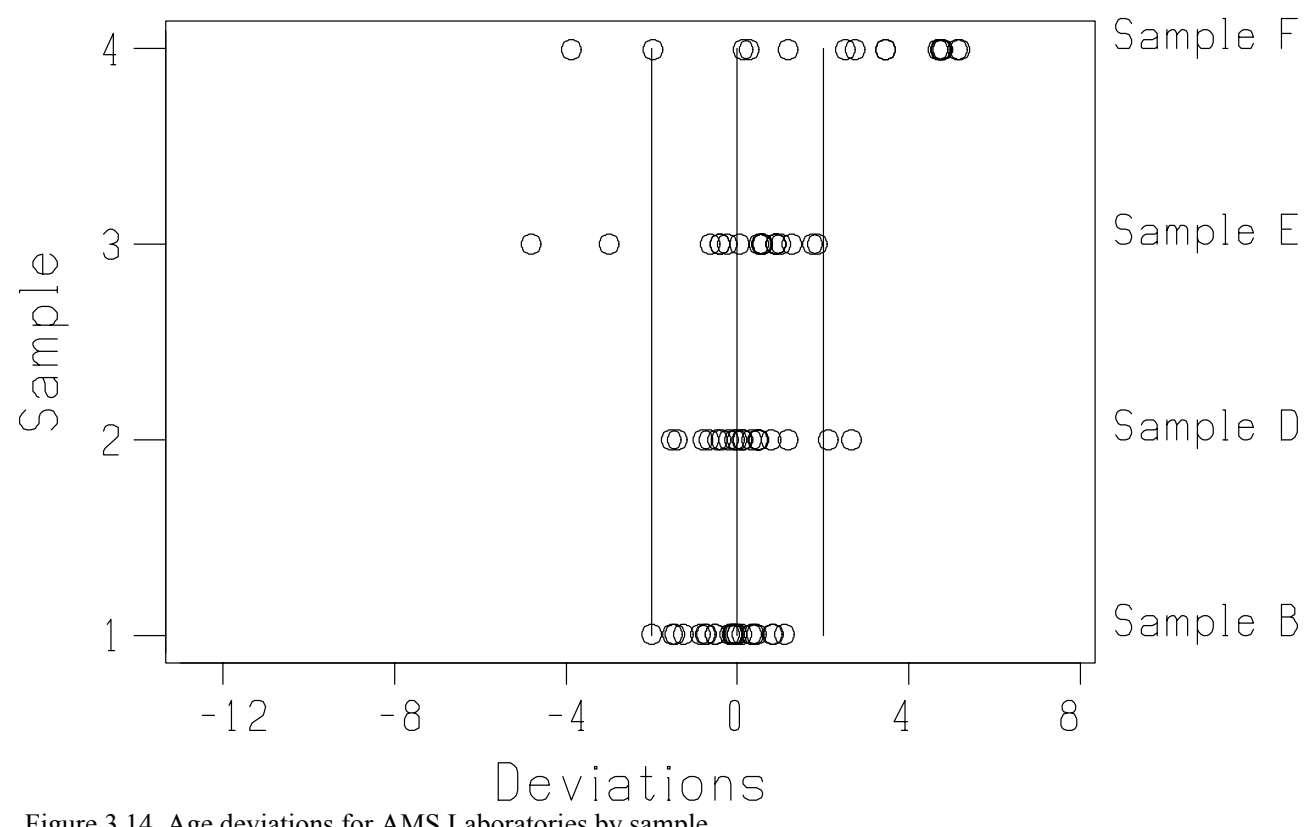

Figure 3.14 Age deviations for AMS Laboratories by sample 


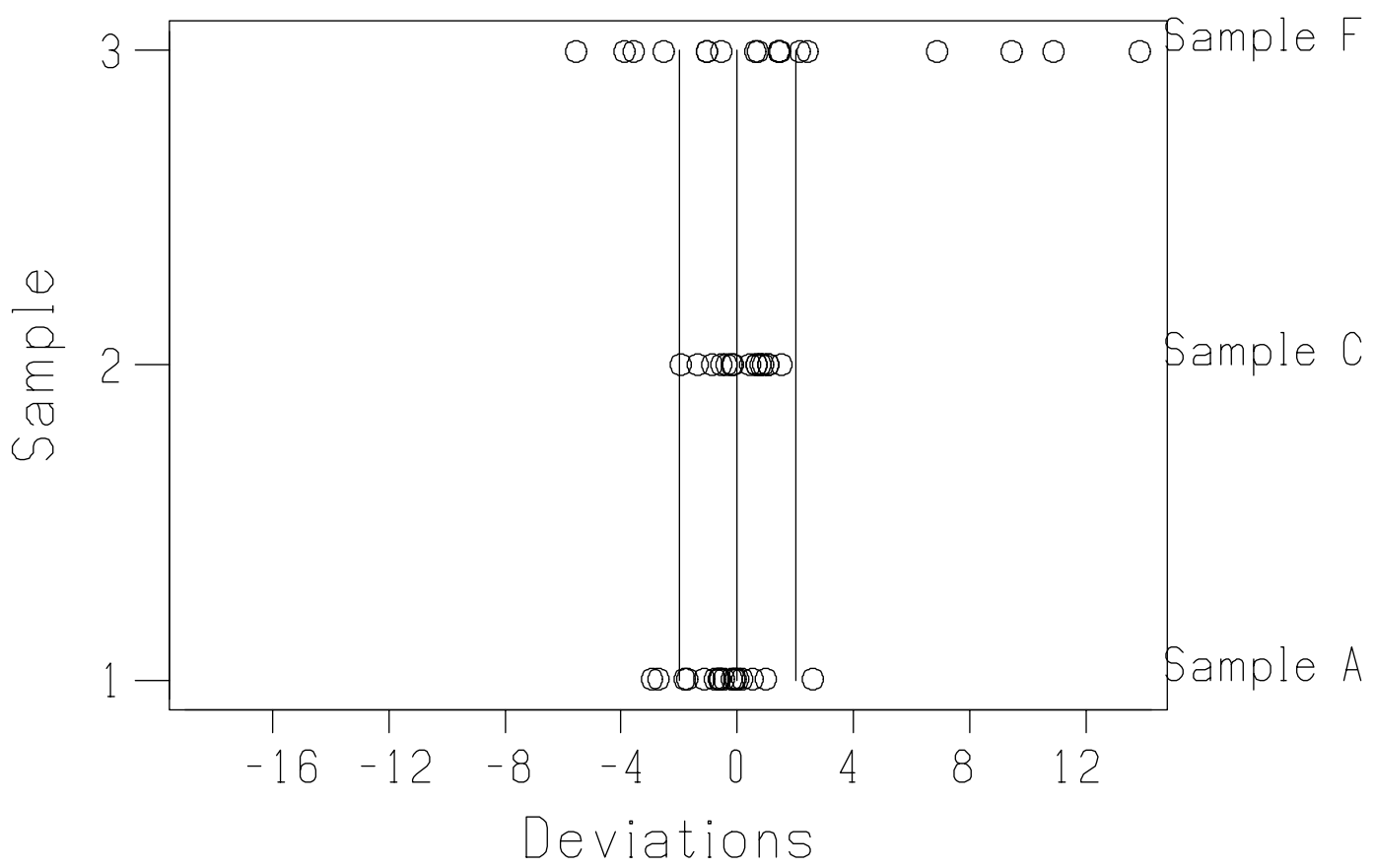

Figure $3.15 \mathrm{pMC}$ deviations for AMS Laboratories by sample

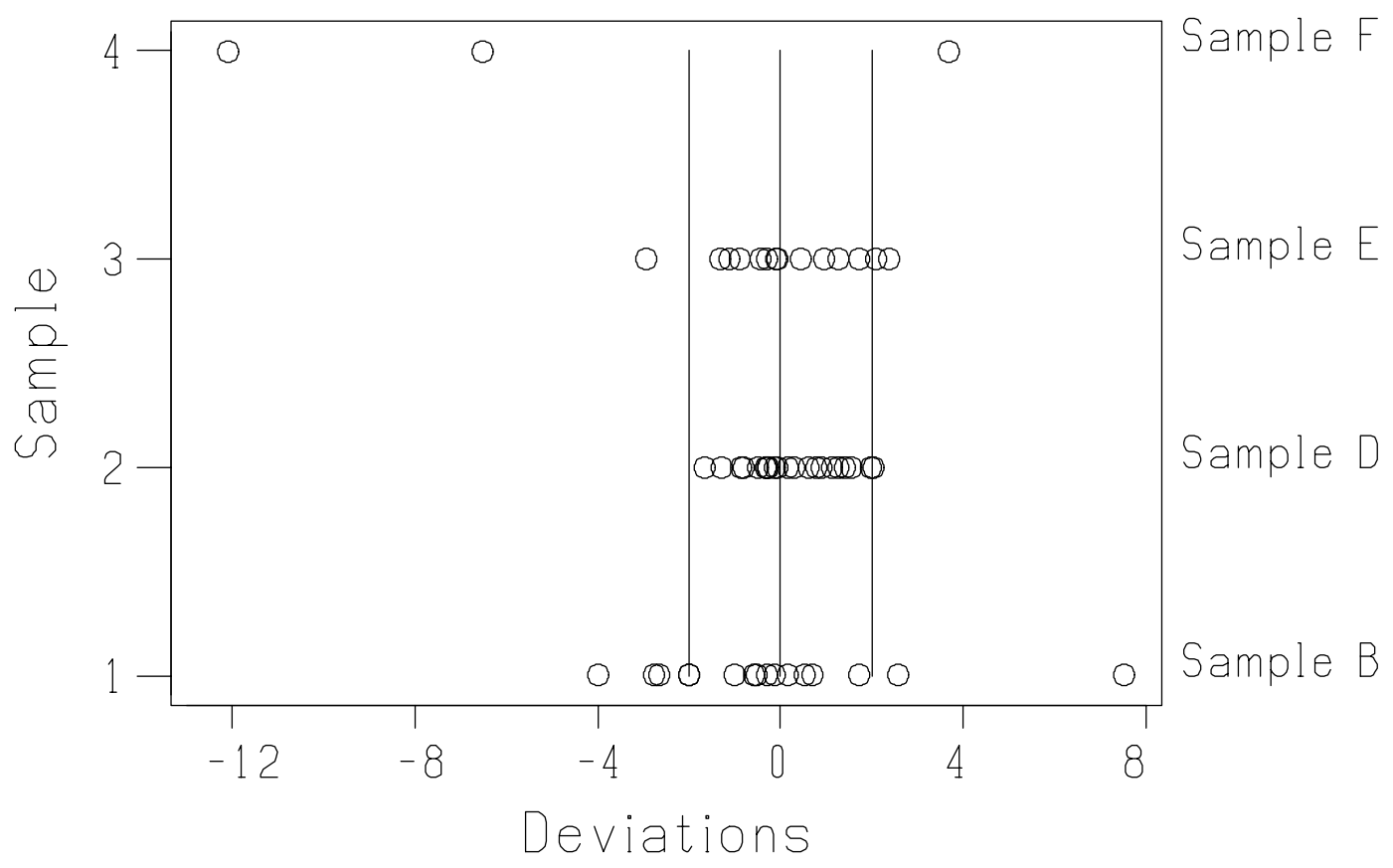

Figure 3.16 Age deviations for GPC laboratories by sample 


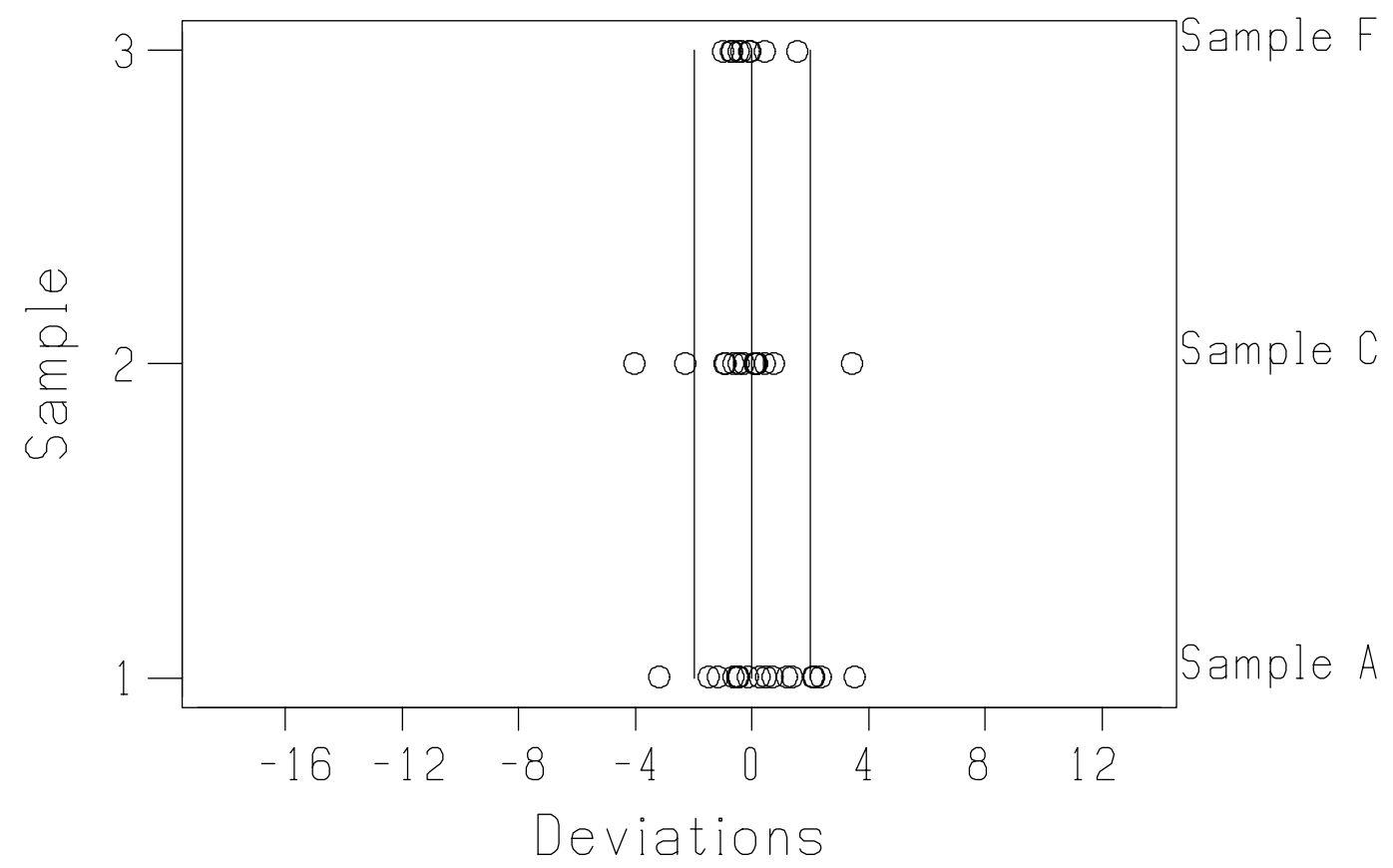

Figure 3.17 pMC deviations for GPC laboratories by sample

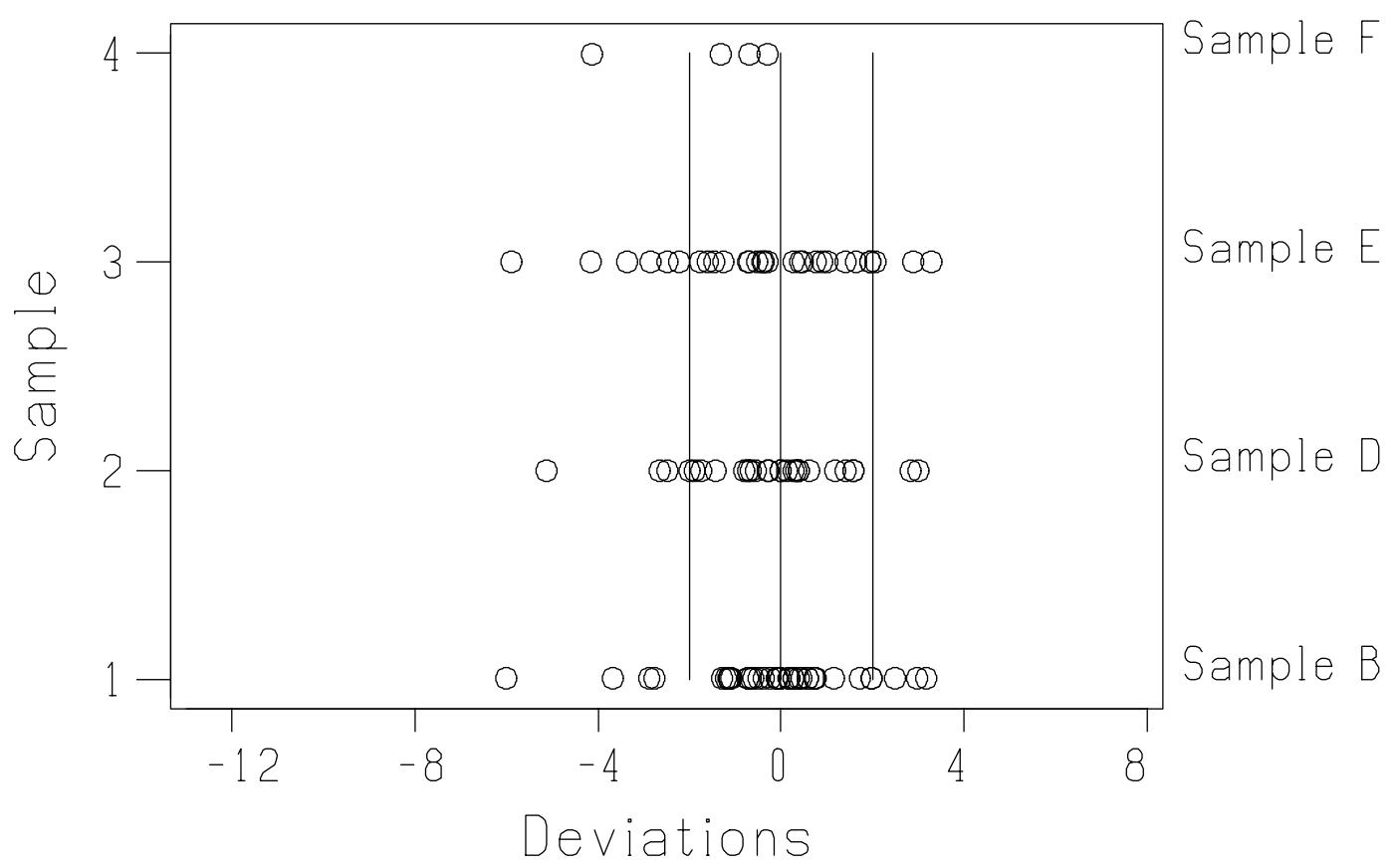

Figure 3.18 Age deviations for LSC laboratories by sample 


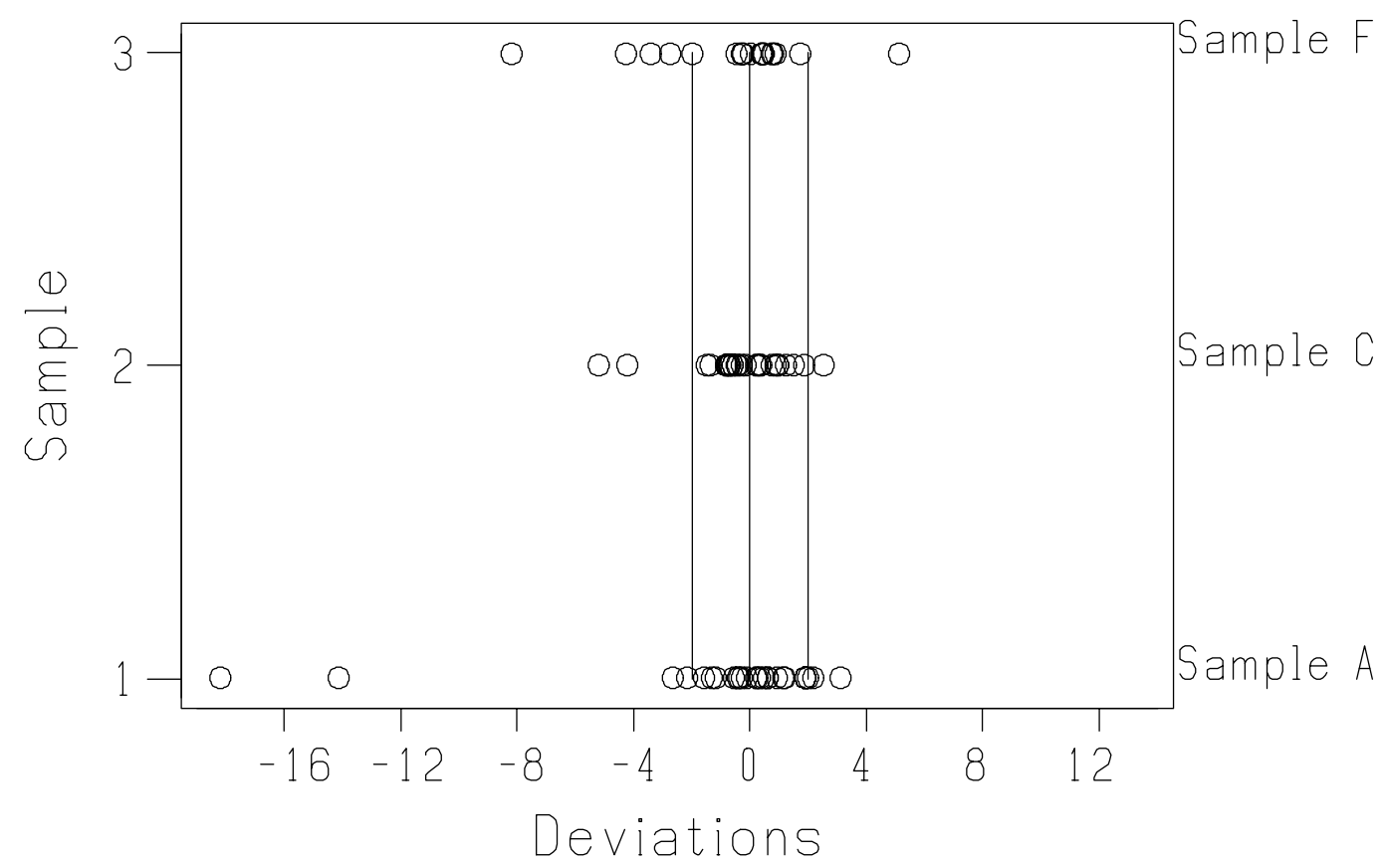

Figure 3.19 pMC deviations for LSC laboratories by sample

\section{RESULTS FOR STAGE 2: OPTIONAL SAMPLES}

\subsection{PARTICIPATING LABORATORIES}

In the second stage of TIRI, a number of optional samples were available and participating labs selected those most appropriate to their dating practices. Seven samples were available and are listed below. Results from a total of 40 laboratories were received for TIRI Stage 2 samples (11 GPC, 25 LSC, 3 AMS, and 1 lab using $\mathrm{CO}_{2}$ absorption). The full results are available in Appendix 4.

Table 4.1 Laboratories participating in Stage 2 of TIRI

\begin{tabular}{lll}
\hline Laboratory name & Country & Laboratory type \\
\hline Datación por Carbono-14 & Spain & LSC \\
Physical Research Lab & India & LSC \\
NLB, Radiocarbon Lab & Germany & GPC \\
Radiocarbon Dating & England & LSC \\
National Museum & Denmark & GPC \\
Weizmann Institute & Israel & GPC \\
Institute of Material Culture & Russia & LSC \\
University of California & USA & GPC \\
University of Texas & USA & LSC \\
SUERC & Scotland & LSC \\
ATOMKI & Hungary & GPC \\
University of Rome & Italy & GPC \\
Institute of Zoology and Botany & Estonia & LSC \\
Saskatchewan Research Council & Canada & LSC \\
Research Lab for Archaeology & England & AMS
\end{tabular}


Table 4.1 Laboratories participating in Stage 2 of TIRI (Continued)

\begin{tabular}{lll}
\hline Laboratory name & Country & Laboratory type \\
\hline Centre de Datation & France & LSC \\
Kyoto Sangyo University & Japan & LSC \\
Tallinn ${ }^{14}$ C lab & Estonia & LSC \\
Illinois Geological Survey & USA & LSC \\
Ruđer Boškovic Institute & Croatia & GPC \\
ICEN/LNETI & Portugal & LSC \\
National Taiwan University & Taiwan & LSC \\
LATYR & Argentina & LSC \\
Bhabha Atomic Research & India & LSC \\
CRAD & Italy & LSC \\
UFZ & Germany & LSC \\
Department of Geology & Wales & GPC \\
Geographical Institute & Russia & LSC \\
Palaeoclimatologie im WIP & Germany & LSC \\
CSIRO & Australia & CARB \\
Department of Geosciences & USA & LSC \\
Scienze della Terra & Italy & LSC \\
Institut für Kernphysik & Germany & GPC \\
DAI & Germany & GPC \\
University of Rome & Italy & LSC \\
NERC ${ }^{14}$ C lab & Scotland & LSC \\
University of Barcelona & Spain & LSC \\
NSF, Arizona AMS & USA & AMS \\
Geological Survey of Canada & Canada & GPC \\
University of Waikato & New Zealand & LSC \\
\hline & \multicolumn{3}{l}{} \\
Table 4.2 Optional samples & \multicolumn{2}{l}{} \\
\hline Sample description & Expected age & \\
\hline G: Fuglaness wood & greater than 4 half-lives \\
H: Ellanmore whole peat & between 2 and 3 half-lives \\
I: travertine & between 1 and 2 half-lives \\
J: Crannog wood & less than 1 half-life \\
K: turbidite carbonate & approximately 3 half-lives \\
L: whalebone & between 2 and 3 half-lives \\
M: Icelandic peat & less than 1 half-life \\
\hline & \multicolumn{2}{l}{} \\
\hline
\end{tabular}

\subsection{SUMMARY STATISTICS}

The individual statistical summaries of the results for each sample are given in the following. The summaries used are the mean and median (the average value); the standard deviation (a measure of the scatter in the results), denoted Stdev; the standard error of the mean (the precision of the average), denoted Semean; the minimum and maximum results; and the lower and upper quartiles (the middle-50\% range of the data), denoted $Q 1$ and $Q 3$. The results for the age have also been summarized graphically using a boxplot (described in Section 3 on the core samples). A number of "outlying" observations are also indicated (marked by *); although at this stage, these results have not been further investigated nor removed from the calculations. 


\subsubsection{Sample G: Fugla Ness Wood Fragments}

The expected age of this sample was greater than 4 half-lives, the sample having been recovered from a peat bed within glacial deposits.

Thirteen laboratories reported a finite age for the sample, 18 laboratories quoted results in the form of "greater than," and 7 simply gave their result as "background."

The results are summarized in Table 4.3.

Table 4.3a Summary of finite ages

\begin{tabular}{rrrrrrrrrl}
\hline Age & $\mathrm{N}$ & Mean & Median & StDev & Semean & Min & Max & Q1 & Q3 \\
\hline & 13 & 41,372 & 42,710 & 5273 & 1463 & 31,800 & 50,510 & 37,460 & 45,450
\end{tabular}

Table 4.3b Summary for censored values

\begin{tabular}{llllllllll}
\hline Age & $\mathrm{N}$ & Mean & Median & StDev & Semean & Min & Max & Q1 & Q3 \\
\hline & 18 & 42,962 & 40,918 & 5826 & 1373 & 35,000 & 54,025 & 39,500 & 47,750 \\
\hline
\end{tabular}

Table 4.3c Summary of other measurement information

\begin{tabular}{lrrllllllll}
\hline & $\mathrm{N}$ & $\mathrm{N}^{*}$ & Mean & Median & StDev & Semean & Min & Max & Q1 & Q3 \\
\hline$\delta^{13} \mathrm{C}$ & 35 & 3 & -26.518 & -26.680 & 1.122 & 0.190 & -28.060 & -23.500 & -27.520 & -25.900 \\
$\delta^{14} \mathrm{C}$ & 28 & 10 & -996.20 & -996.75 & 3.86 & 0.73 & -1000.50 & -981.70 & -998.50 & -995.16 \\
$\Delta^{14} \mathrm{C}$ & 28 & 10 & -995.39 & -996.52 & 4.72 & 0.89 & -1000.50 & -980.80 & -998.47 & -993.57 \\
\hline
\end{tabular}

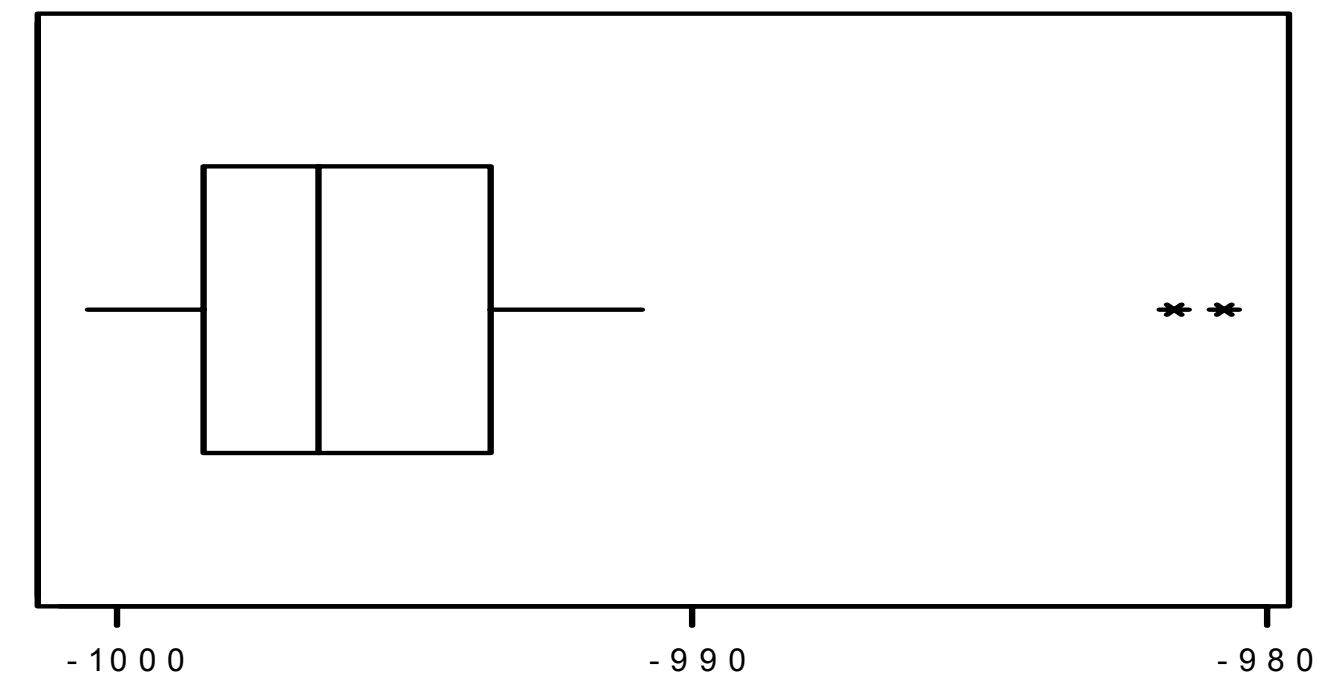

Figure 4.1 Distribution of $\Delta^{14} \mathrm{C}$ for Sample G

\subsubsection{Sample H: Ellanmore Whole Peat (Raw Material of Sample E in Stage 1)}

The expected age for this sample is between 2 and 3 half-lives. In the earlier stage, the humic acid extract from the bulk was supplied as Sample E. The previous mean result was 11,066 yr BP. 
Table 4.4 Summary statistics for Sample H

\begin{tabular}{llcccc}
\hline & $\mathrm{N}$ & $\mathrm{N}^{*}$ & Mean & Median & StDev \\
\hline$\delta^{13} \mathrm{C}$ & 33 & 2 & -28.392 & -28.600 & 0.679 \\
$\delta^{14} \mathrm{C}$ & 24 & 11 & -749.25 & -749.53 & 9.95 \\
$\Delta^{14} \mathrm{C}$ & 32 & 3 & -749.41 & -749.99 & 9.45 \\
Age & 35 & 0 & 11,115 & 11,130 & 311 \\
Error & 35 & 0 & 115.5 & 100.0 & 90.9 \\
\hline \multicolumn{7}{r}{} & & & & \\
& Semean & Min & Max & $\mathrm{Q} 1$ & $\mathrm{Q} 3$ \\
\hline$\delta^{13} \mathrm{C}$ & 0.118 & -29.200 & -26.200 & -28.800 & -28.050 \\
$\delta^{14} \mathrm{C}$ & 2.03 & -772.90 & -723.90 & -756.00 & -745.04 \\
$\Delta^{14} \mathrm{C}$ & 1.67 & -771.50 & -722.10 & -754.65 & -744.27 \\
Age & 53 & 10,280 & 11,860 & 10,915 & 11,300 \\
Error & 15.4 & 25.0 & 580.0 & 70.0 & 140.0 \\
\hline
\end{tabular}

From the table, it can be seen that the range of results is approximately $1000 \mathrm{yr}$ and that the mean age is 11,115 yr. The middle $50 \%$ of the data lie between 10,915 and $11,300 \mathrm{yr}$, a span of approximately $380 \mathrm{yr}$. A $95 \%$ confidence interval for the "true" age is 11,008-11,221 yr BP.

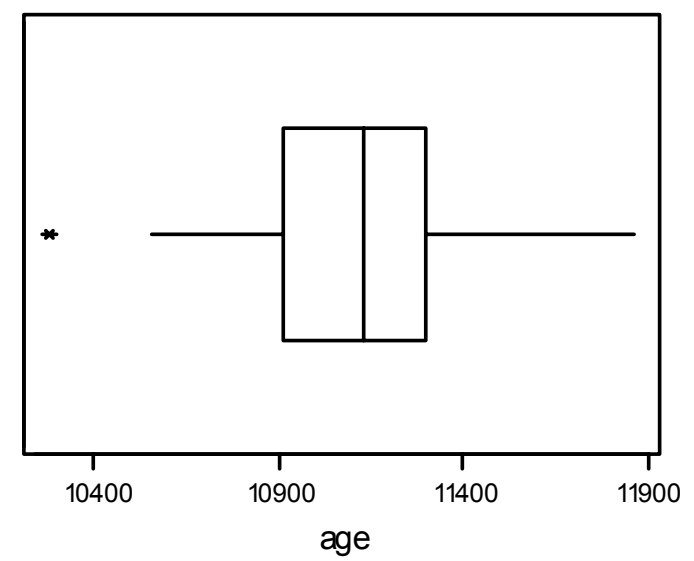

Figure 4.2 Distribution of age for Sample H

\subsubsection{Sample I: Travertine}

This sample had an expected age between 1 and 2 half-lives

Table 4.5 Summary statistics for Sample I

\begin{tabular}{llcccc}
\hline & $\mathrm{N}$ & $\mathrm{N}^{*}$ & Mean & Median & \multicolumn{1}{c}{ StDev } \\
\hline$\delta^{13} \mathrm{C}$ & 32 & 2 & -9.556 & -9.900 & 1.224 \\
$\delta^{14} \mathrm{C}$ & 24 & 10 & -740.42 & -740.06 & 5.82 \\
$\Delta^{14} \mathrm{C}$ & 31 & 3 & -747.09 & -748.00 & 8.51 \\
Age & 34 & 0 & 11,034 & 11,073 & 276 \\
Error & 34 & 0 & 126.9 & 100.0 & 114.1 \\
\hline \multicolumn{7}{r}{} & & & & \\
& Semean & Min & Max & $\mathrm{Q} 1$ & $\mathrm{Q} 3$ \\
\hline$\delta^{13} \mathrm{C}$ & 0.216 & -10.700 & -4.100 & -9.958 & -9.690 \\
$\delta^{14} \mathrm{C}$ & 1.19 & -755.14 & -730.40 & -741.82 & -736.30 \\
$\Delta^{14} \mathrm{C}$ & 1.53 & -762.45 & -711.92 & -750.40 & -743.90 \\
Age & 47 & 9990 & 11,550 & 10,931 & 11,144 \\
Error & 19.6 & 35.0 & 570.0 & 70.8 & 132.5 \\
\hline
\end{tabular}


The average age is $11,034 \mathrm{yr} \mathrm{BP}$, with a range of $1500 \mathrm{yr}$ based on 34 results. The middle $50 \%$ of the data lie in a range 10,931-11,144, a span of approximately $250 \mathrm{yr}$. A $95 \%$ confidence interval for the true age is $10,937-11,130$.

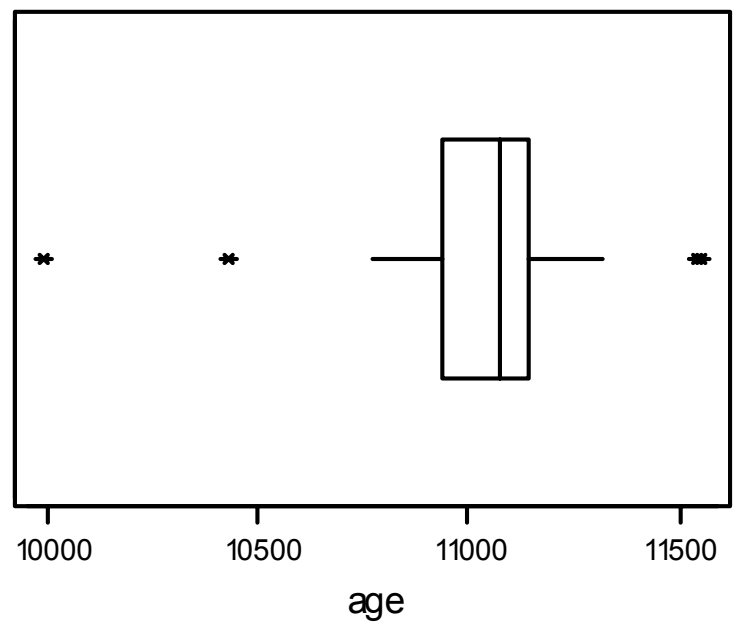

Figure 4.3 Distribution of age for TIRI-I

Three observations are highlighted as extreme, but it is clear that the middle $50 \%$ range is relatively tight.

\subsubsection{Sample J: Wood, Expected Age Less Than 1 Half-Life}

Table 4.6 Summary statistics

\begin{tabular}{lccccc}
\hline & $\mathrm{N}$ & $\mathrm{N}$ & Mean & Median & StDev \\
\hline$\delta^{13} \mathrm{C}$ & 33 & 3 & -26.579 & -26.800 & 1.147 \\
$\delta^{14} \mathrm{C}$ & 26 & 10 & -184.03 & -185.50 & 12.88 \\
$\Delta^{14} \mathrm{C}$ & 31 & 5 & -178.89 & -179.80 & 12.66 \\
Age & 36 & 0 & 1593.0 & 1597.5 & 119.1 \\
Error & 36 & 0 & 49.97 & 45.00 & 18.57 \\
\hline \multicolumn{7}{r}{} & & & & \\
& Semean & Min & Max & $\mathrm{Q} 1$ & $\mathrm{Q} 3$ \\
\hline$\delta^{13} \mathrm{C}$ & 0.200 & -28.200 & -22.490 & -27.400 & -25.975 \\
$\delta^{14} \mathrm{C}$ & 2.53 & -211.88 & -149.70 & -189.93 & -175.82 \\
$\Delta^{14} \mathrm{C}$ & 2.27 & -209.91 & -147.10 & -186.60 & -172.00 \\
Age & 19.9 & 1315.0 & 1890.0 & 1522.5 & 1660.0 \\
Error & 3.09 & 10.00 & 82.00 & 37.75 & 65.75 \\
\hline
\end{tabular}

The average age is $1593 \mathrm{yr}$, with the range of results approximately $500 \mathrm{yr}$. The mid-50\% span is $1522-1660$, a spread of $140 \mathrm{yr}$. A $95 \%$ confidence interval for the true age is $1553-1633$.

The boxplot shows a highly symmetrical distribution with 2 extreme observations (1 low, 1 high). 


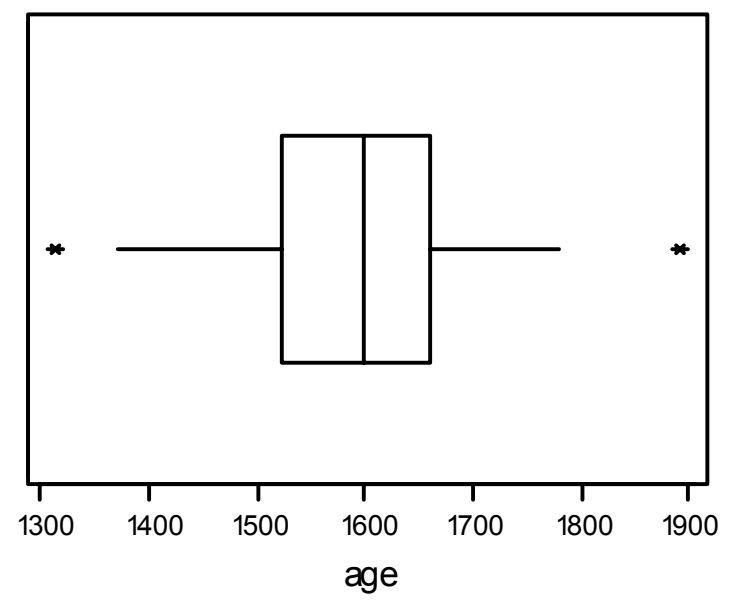

Figure 4.4 Distribution of age for TIRI-J

\subsubsection{Sample K: Turbidite Carbonate, Expected Age of 3 Half-Lives}

Table 4.7 Summary statistics for Sample K

\begin{tabular}{|c|c|c|c|c|c|}
\hline & $\mathrm{N}$ & $\mathrm{N}^{*}$ & Mean & Median & StDev \\
\hline$\delta^{13} \mathrm{C}$ & 28 & 2 & 1.321 & 1.100 & 1.260 \\
\hline$\delta^{14} \mathrm{C}$ & 22 & 8 & -890.57 & -890.35 & 5.21 \\
\hline$\Delta^{14} \mathrm{C}$ & 27 & 32 & -895.8 & -895.3 & 10.8 \\
\hline Age & 30 & 0 & 18,166 & 18,147 & 928 \\
\hline \multirow[t]{2}{*}{ Error } & 30 & 0 & 237.8 & 150.0 & 360.7 \\
\hline & Semean & Min & Max & Q1 & Q3 \\
\hline$\delta^{13} \mathrm{C}$ & 0.238 & 0.000 & 7.300 & 0.863 & 1.475 \\
\hline$\delta^{14} \mathrm{C}$ & 1.11 & -898.90 & 876.30 & -894.78 & -887.85 \\
\hline$\Delta^{14} \mathrm{C}$ & 2.1 & -933.1 & -863.3 & -899.9 & -892.9 \\
\hline Age & 169 & 15,980 & 21,700 & 17,986 & 18,522 \\
\hline Error & 65.9 & 80.0 & 2100.0 & 110.0 & 216.2 \\
\hline
\end{tabular}

The average age is $18,166 \mathrm{yr} \mathrm{BP}$, with an observed range of approximately $5000 \mathrm{yr}$ in the results. The mid- $50 \%$ lies in the range of $17,986-18,522$, a span of just over $500 \mathrm{yr}$. A $95 \%$ confidence interval for the true age is $17,820-18,513 \mathrm{BP}$.

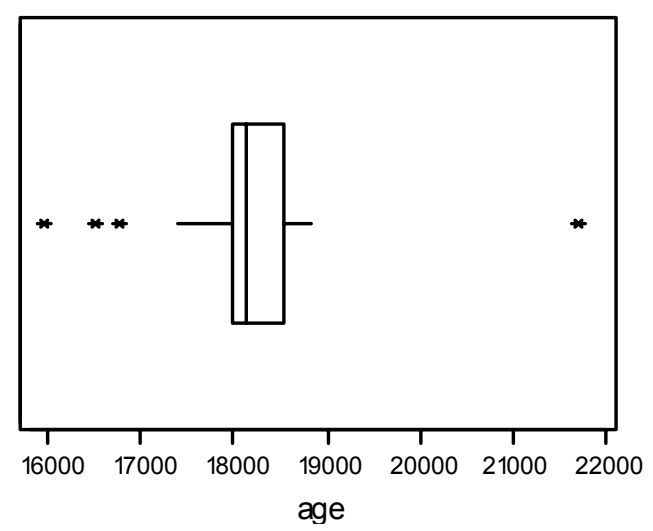

Figure 4.5 Distribution of age for TIRI-K 
The boxplot identifies several extreme observations.

\subsubsection{Sample L: Whalebone, Expected Age Between 2 and 3 Half-Lives}

Table 4.8 Summary statistics for Sample L

\begin{tabular}{lllccc}
\hline & $\mathrm{N}$ & $\mathrm{N} *$ & Mean & Median & StDev \\
\hline$\delta^{13} \mathrm{C}$ & 21 & 2 & -15.06 & -14.770 & 1.602 \\
$\delta^{14} \mathrm{C}$ & 17 & 6 & -789.04 & -789.10 & 9.18 \\
$\Delta^{14} \mathrm{C}$ & 18 & 5 & -792.61 & -793.25 & 8.48 \\
Age & 23 & 0 & 12,605 & 12,680 & 449 \\
Error & 23 & 0 & 127.5 & 110.0 & 72.1 \\
\hline \multicolumn{7}{r}{} & & & & \\
& Semean & Min & Max & $\mathrm{Q} 1$ & $\mathrm{Q} 3$ \\
\hline$\delta^{13} \mathrm{C}$ & 0.35 & -19.400 & -13.200 & -15.305 & -14.15 \\
$\delta^{14} \mathrm{C}$ & 2.23 & -800.00 & -762.00 & -795.68 & -786.15 \\
$\Delta^{14} \mathrm{C}$ & 2.00 & -804.00 & -767.00 & -799.02 & -789.90 \\
Age & 94 & 11,050 & 13,091 & 12,580 & 12,900 \\
Error & 15.0 & 40.0 & 310.0 & 70.0 & 154.0 \\
\hline
\end{tabular}

The average age is $12,600 \mathrm{yr} \mathrm{BP}$ and the full spread of results is $2000 \mathrm{yr}$. The mid-50\% of the data lie in the range of $12,580-12,900$, a span of $320 \mathrm{yr}$. A $95 \%$ confidence interval for the true age is $12,410-12,799$ BP.

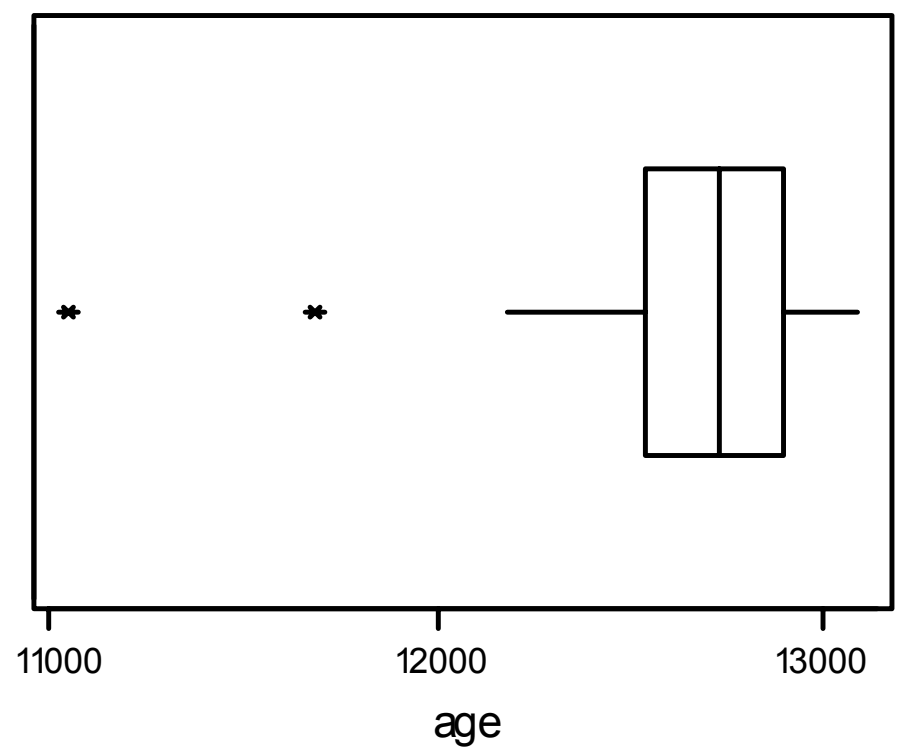

Figure 4.6 Distribution of age for TIRI-L

Two low values are identified under 12,000 yr BP. 


\subsubsection{Sample M: Peat, Expected Age Less Than 1 Half-Life}

Table 4.9 Summary statistics for Sample M

\begin{tabular}{lllccc}
\hline & $\mathrm{N}$ & $\mathrm{N}^{*}$ & Mean & Median & StDev \\
\hline$\delta^{13} \mathrm{C}$ & 28 & 2 & -28.178 & -28.150 & 0.841 \\
$\delta^{14} \mathrm{C}$ & 22 & 8 & -212.07 & -196.95 & 41.05 \\
$\Delta^{14} \mathrm{C}$ & 27 & 3 & -203.45 & -189.00 & 39.04 \\
Age & 29 & 1 & 1842.8 & 1710.0 & 408.9 \\
Error & 29 & 1 & 83.6 & 60.0 & 63.7 \\
\hline \multicolumn{7}{l}{} & & & & \\
& Semean & Min & Max & $\mathrm{Q} 1$ & $\mathrm{Q} 3$ \\
\hline$\delta^{13} \mathrm{C}$ & 0.159 & -29.800 & -26.600 & -28.792 & -27.800 \\
$\delta^{14} \mathrm{C}$ & 8.75 & -361.38 & -169.40 & -219.94 & -189.50 \\
$\Delta^{14} \mathrm{C}$ & 7.51 & -358.79 & -165.20 & -212.43 & -184.50 \\
Age & 75.9 & 1448.0 & 3570.0 & 1642.5 & 1920.0 \\
Error & 11.8 & 30.0 & 250.0 & 44.0 & 95.0 \\
\hline
\end{tabular}

The average age is $1842 \mathrm{yr} \mathrm{BP}$, the spread of results is $2000 \mathrm{yr}$, with the mid-50\% lying between $1642-1920$, a span of $300 \mathrm{yr}$. The $95 \%$ confidence interval for the true age is 1687-1998 BP.

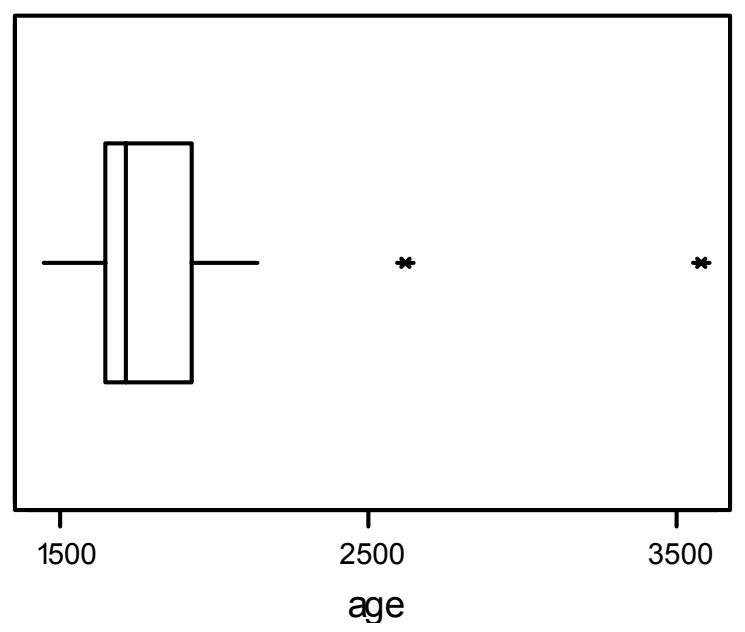

Figure 4.7 Distribution of age for TIRI-M

Two extreme observations over $2500 \mathrm{yr}$ are identified and contribute to the very large range observed.

\subsection{ANALYSIS AND CONCLUSIONS}

If we calculate the coefficient of variation (defined as StDev / Mean $\times 100$ ), then we gain an impression of the variability in the results relative to the mean. In this way, we can also compare more directly the results for the different samples. 
Table 4.10 Material coefficient of variations

\begin{tabular}{llllll}
\hline Sample & Material & Mean (BP) & Span of results & Mid-50\% span & CV(\%) \\
\hline G & wood & 41,372 & 18,710 & 7990 & 12.7 \\
H & whole peat & 11,115 & 1580 & 385 & 2.8 \\
I & travertine & 11,034 & 1560 & 213 & 2.5 \\
J & wood & 1590 & 575 & 138 & 7.4 \\
K & turbidite carbonate & 18,166 & 5720 & 536 & 5.1 \\
L & whalebone & 12,601 & 2041 & 320 & 3.6 \\
M & Icelandic peat & 1842 & 2122 & 278 & 22.2 \\
\hline
\end{tabular}

Comparing the results, we see that the 2 most variable samples (relative to their average age) are $\mathrm{G}$ (Fugla Ness wood) and M (Icelandic peat), followed by J (Crannog wood), and then K (turbidite carbonate). These differences will reflect in part the natural sample variability, and so are wholly realistic.

The span of results for Sample G is large, reflecting the fact that this sample is close to background for many laboratories and, again, emphasizes the fact that at this level of activity, differences between laboratories are emphasized. For Sample J, we see a large span relative to the age, but that the mid- $50 \%$ span is pleasingly tight. The large span of results is perhaps surprising given that the sample was cut from a single timber (roughly 50-yr growth). For Sample M, (of a roughly equivalent age to $\mathrm{J}$ ), the span of all results is considerably larger, though the mid-50\% span is approximately the same as J. The overall span can, of course, be heavily influenced by small numbers of extreme observations. For the rest-Samples H, I, and L — they are virtually identical in terms of range of results. Thus, it seems unlikely that there have been any particular problems linked to the dating of bone. Sample K shows a wider range of results, though the mid-50\% span is just over $500 \mathrm{yr}$ relative to an age of approximately $18,000 \mathrm{yr}$.

\subsection{CONSENSUS VALUES}

Consensus values for each sample were evaluated using the same method used in the characterization of the IAEA reference samples (Rozanski et al. 1992) and for the core samples.

Table 4.11 Consensus values for optional samples

\begin{tabular}{lcc}
\hline Sample & Consensus value $(\mathrm{BP})$ & Estimated precision $(1 \sigma)$ \\
\hline G: Fuglaness wood & 39,784 & 620 \\
H: Ellanmore whole peat & 11,152 & 23 \\
I: travertine & 11,060 & 17 \\
J: Crannog wood & 1605 & 8 \\
K: turbidite carbonate & 18,155 & 34 \\
L: whalebone & 12,788 & 30 \\
M: Icelandic peat & 1682 & 15 \\
\hline
\end{tabular}

For each sample, a number of outliers were removed (up to a maximum of 10, but more typically less than 5). When the consensus value was calculated, results were also omitted due to the $\pm 2 \sigma$ criterion not being satisfied.

Similar to the presentation for core samples, Figures 4.8-4.14 show individual laboratory differences from the consensus value. Figures 4.15-4.16 show the deviations for LSC and GPC laboratories. There is no such figure for AMS laboratories, since too few participated in the optional 
program. These latter plots again show up to 1 or 2 large deviations for a number of the samples, but there is no evidence of any significant difference in performance overall for the 2 laboratory types. The figures again demonstrate that Sample G (at close to background) was the most scattered.

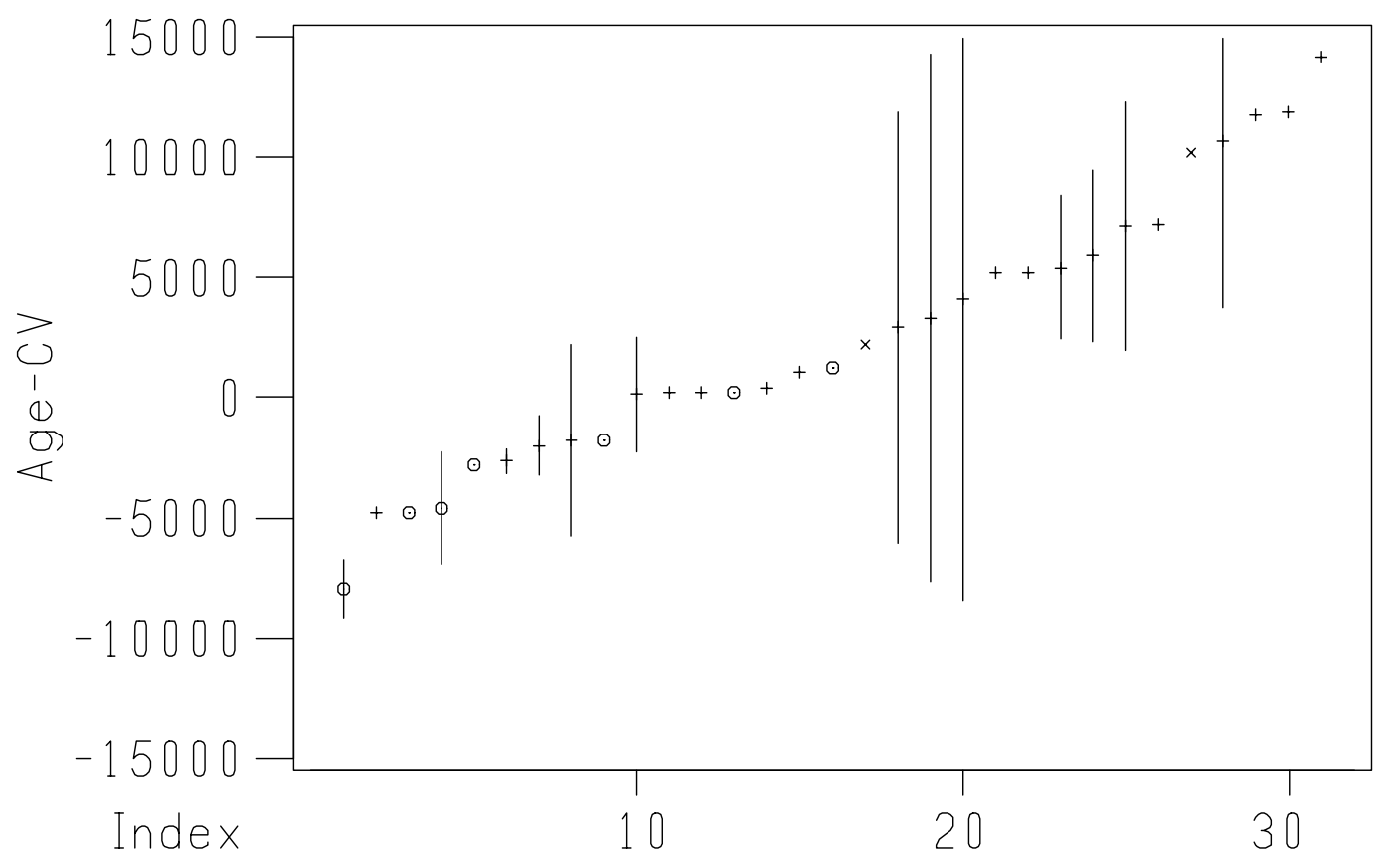

Figure 4.8 Sample G: Fuglaness wood

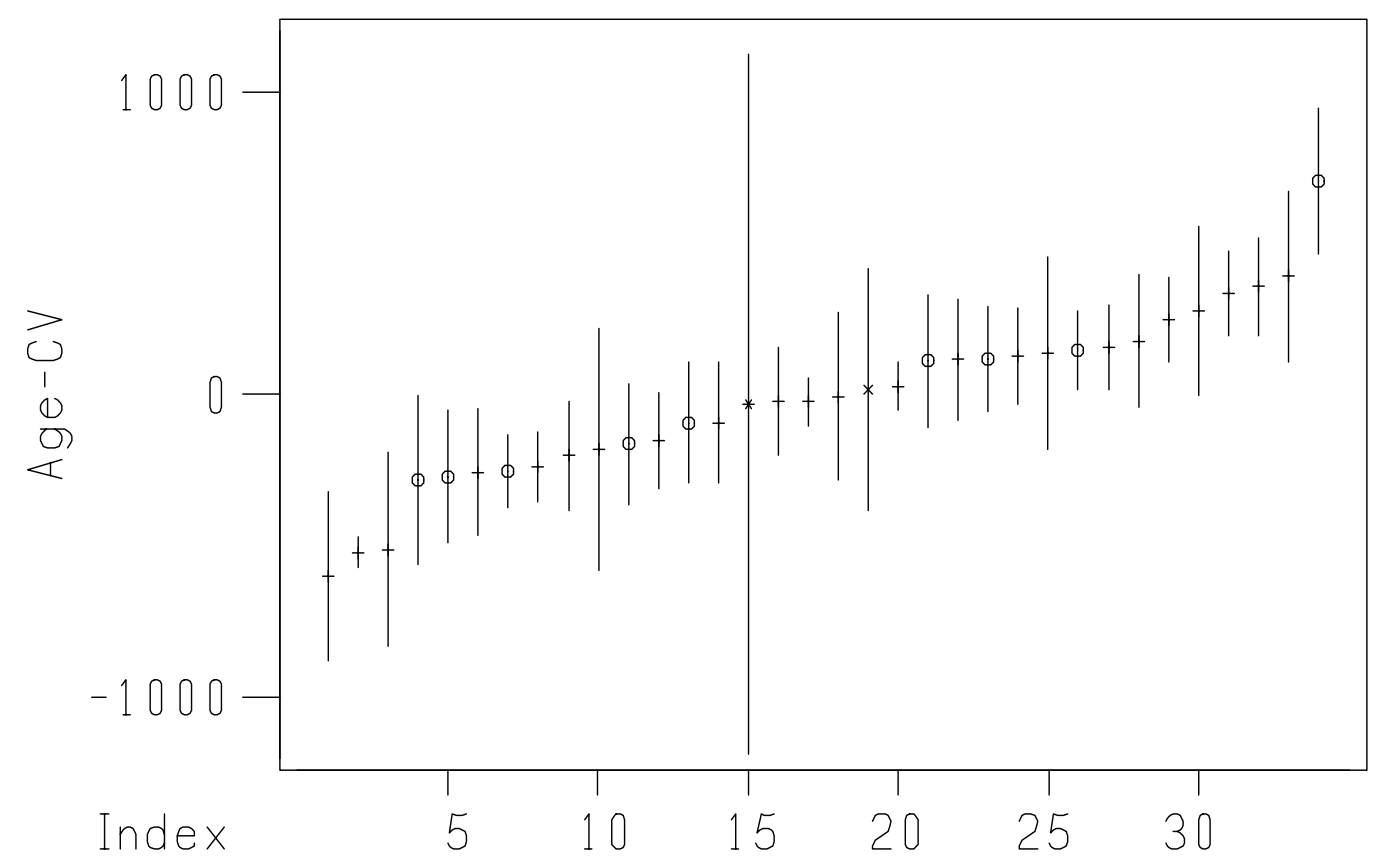

Figure 4.9 Sample H: Ellanmore peat 


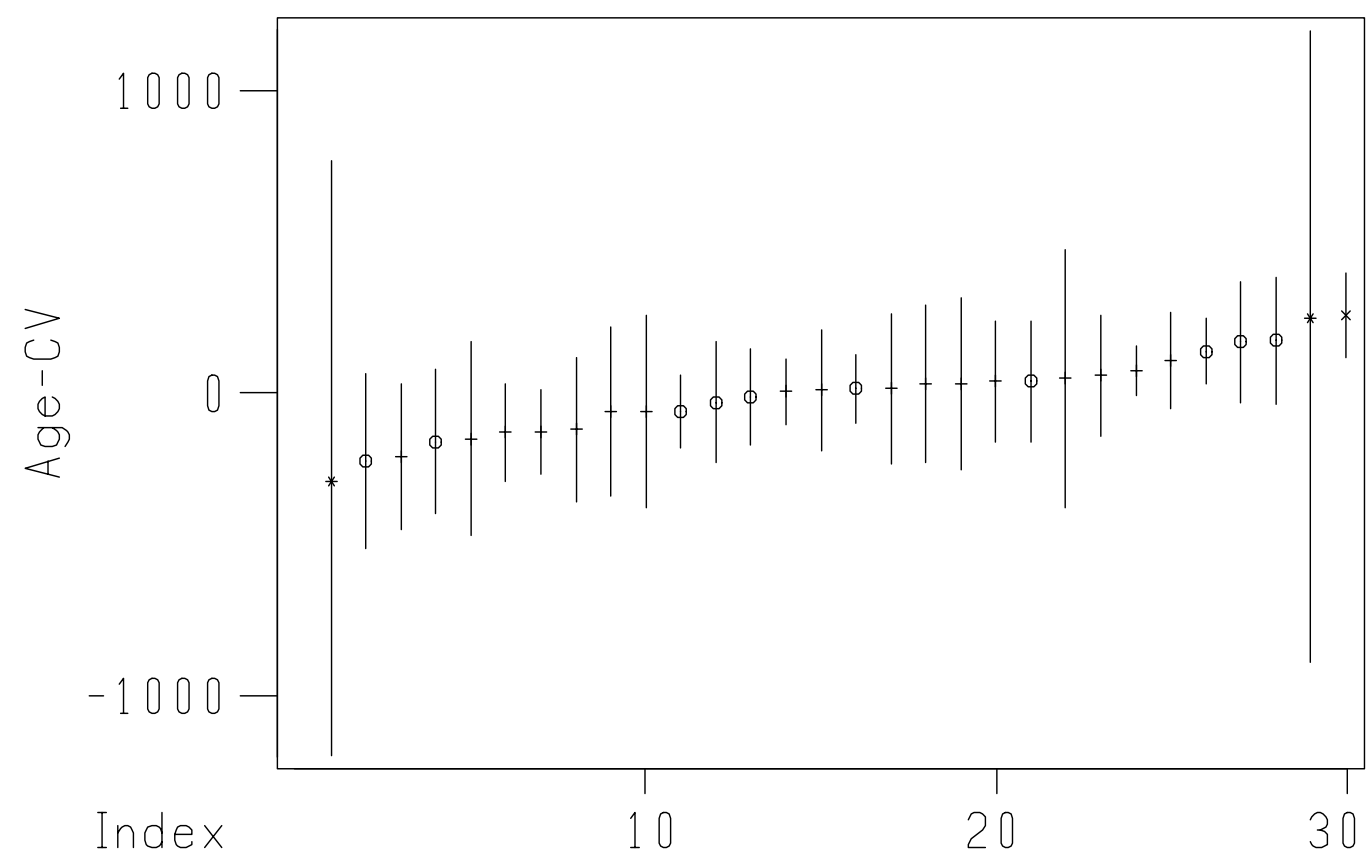

Figure 4.10 Sample I: travertine

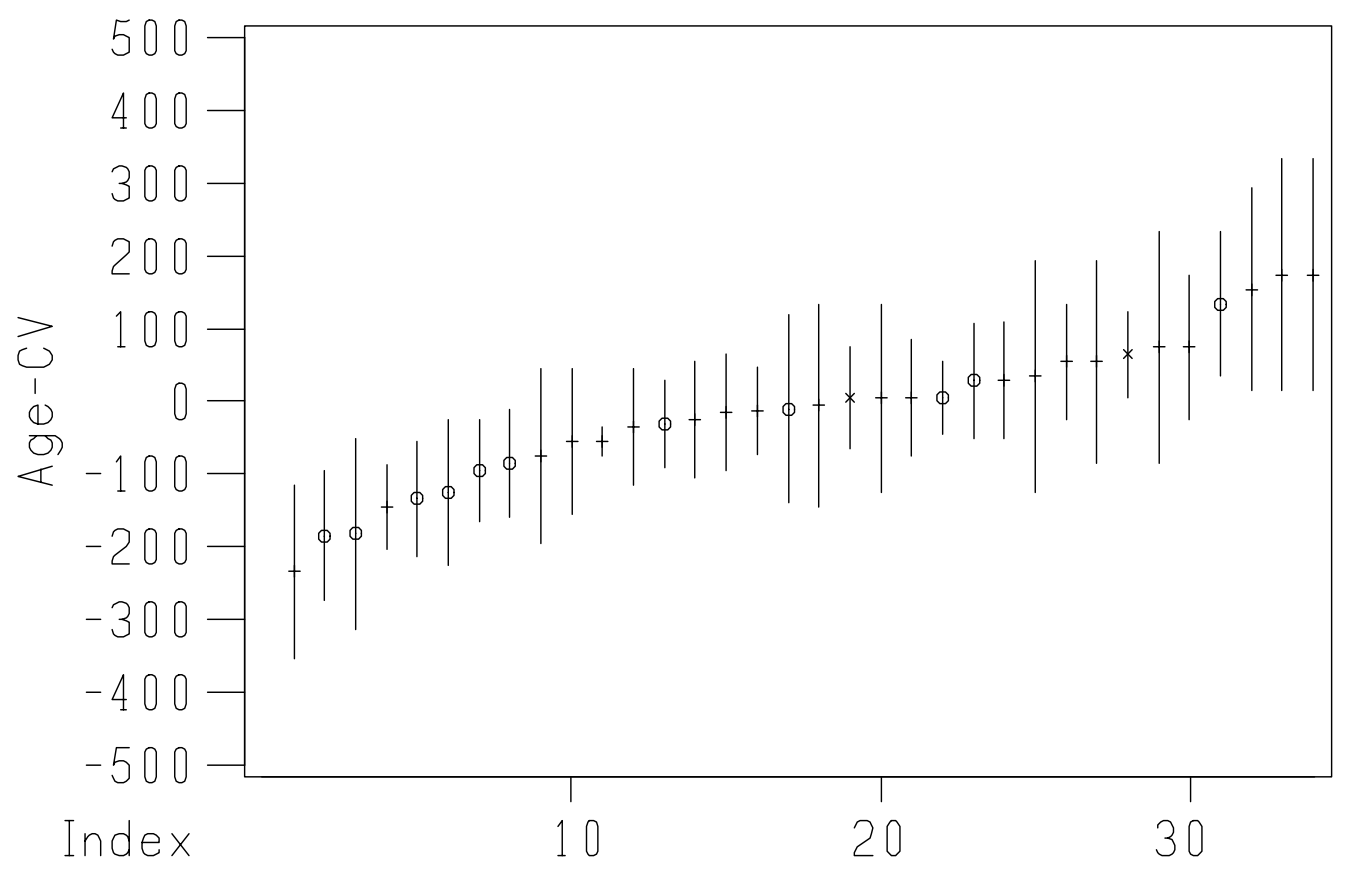

Figure 4.11 Sample J: wood (Buiston Crannog) 


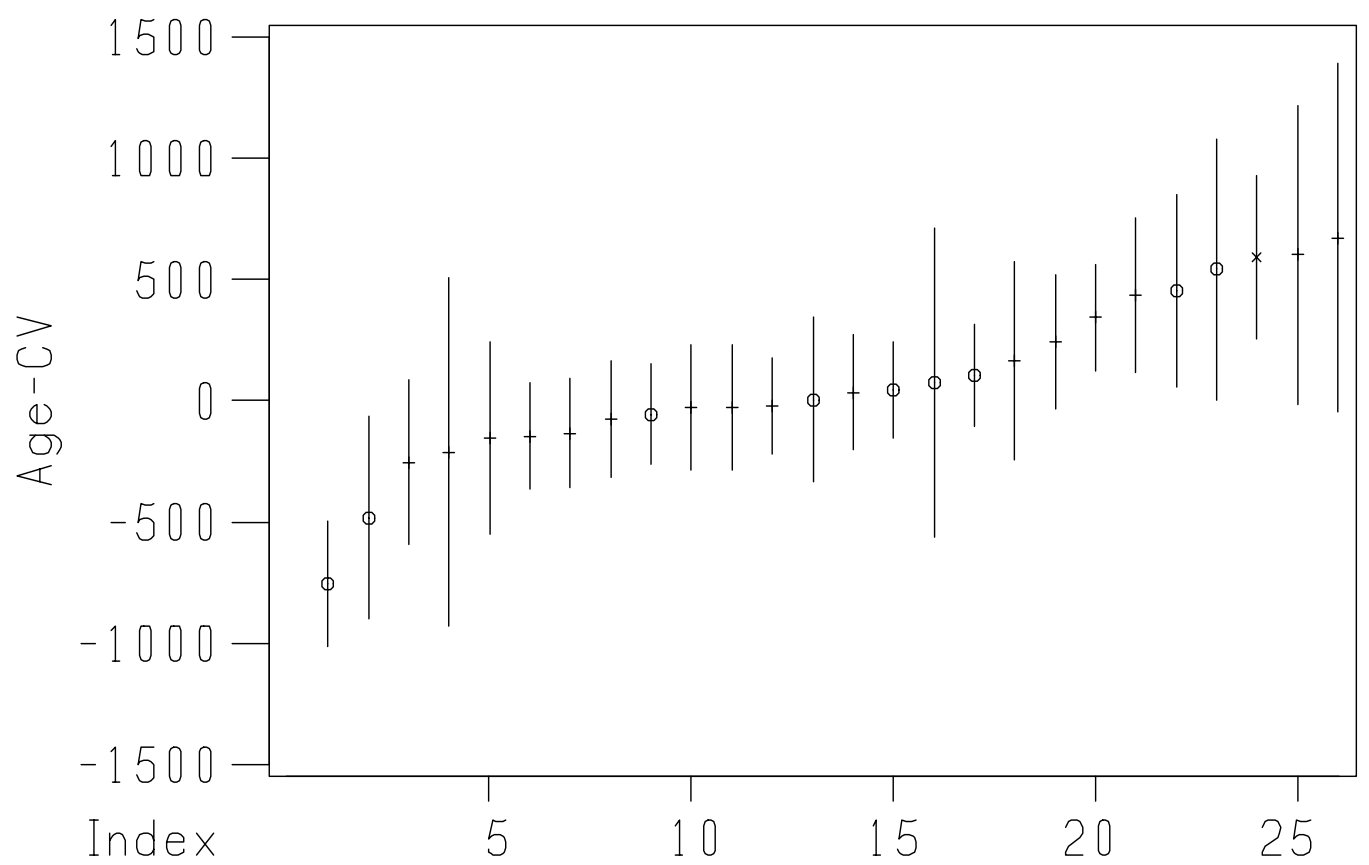

Figure 4.12 Sample K: turbidite carbonate

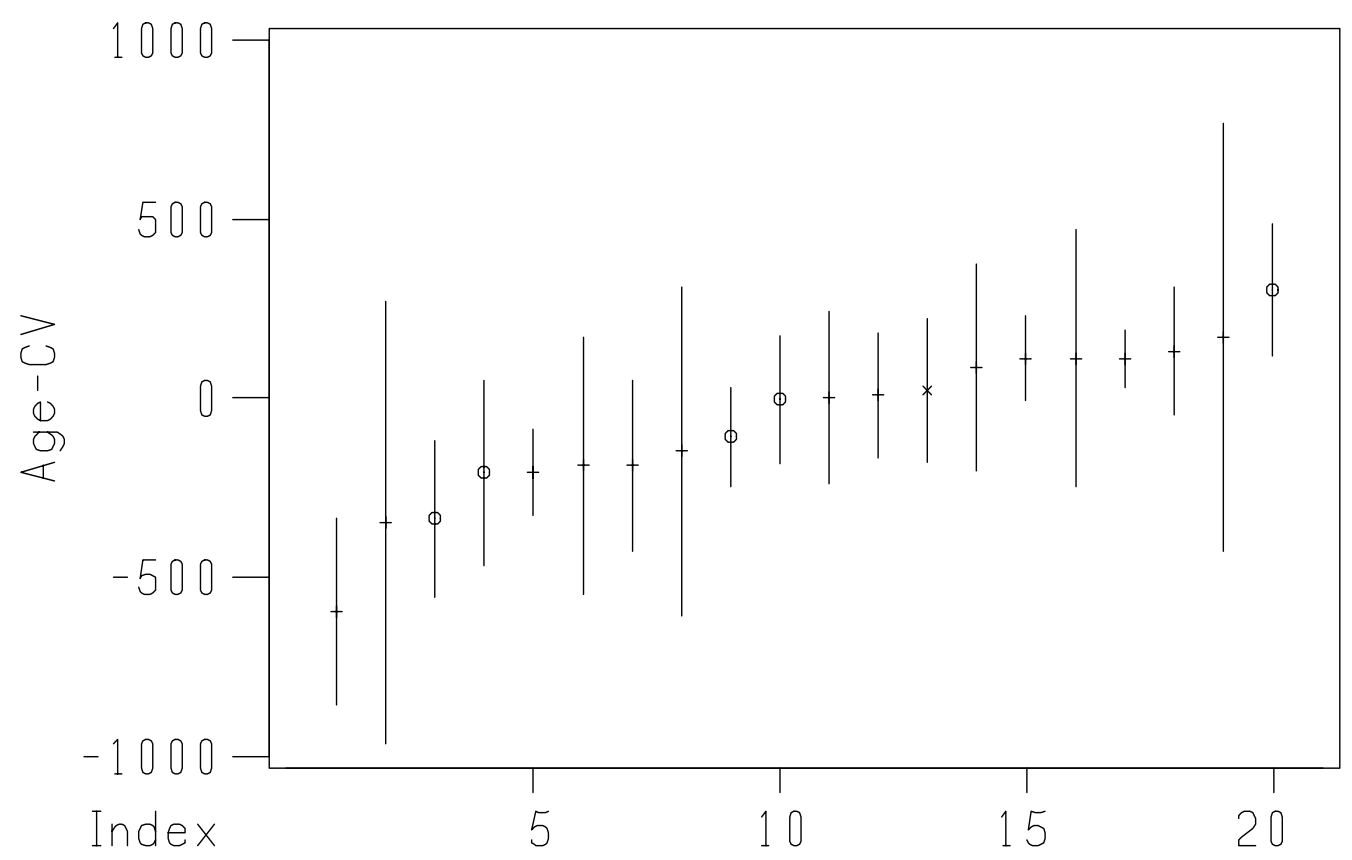

Figure 4.13 Sample L: whalebone 


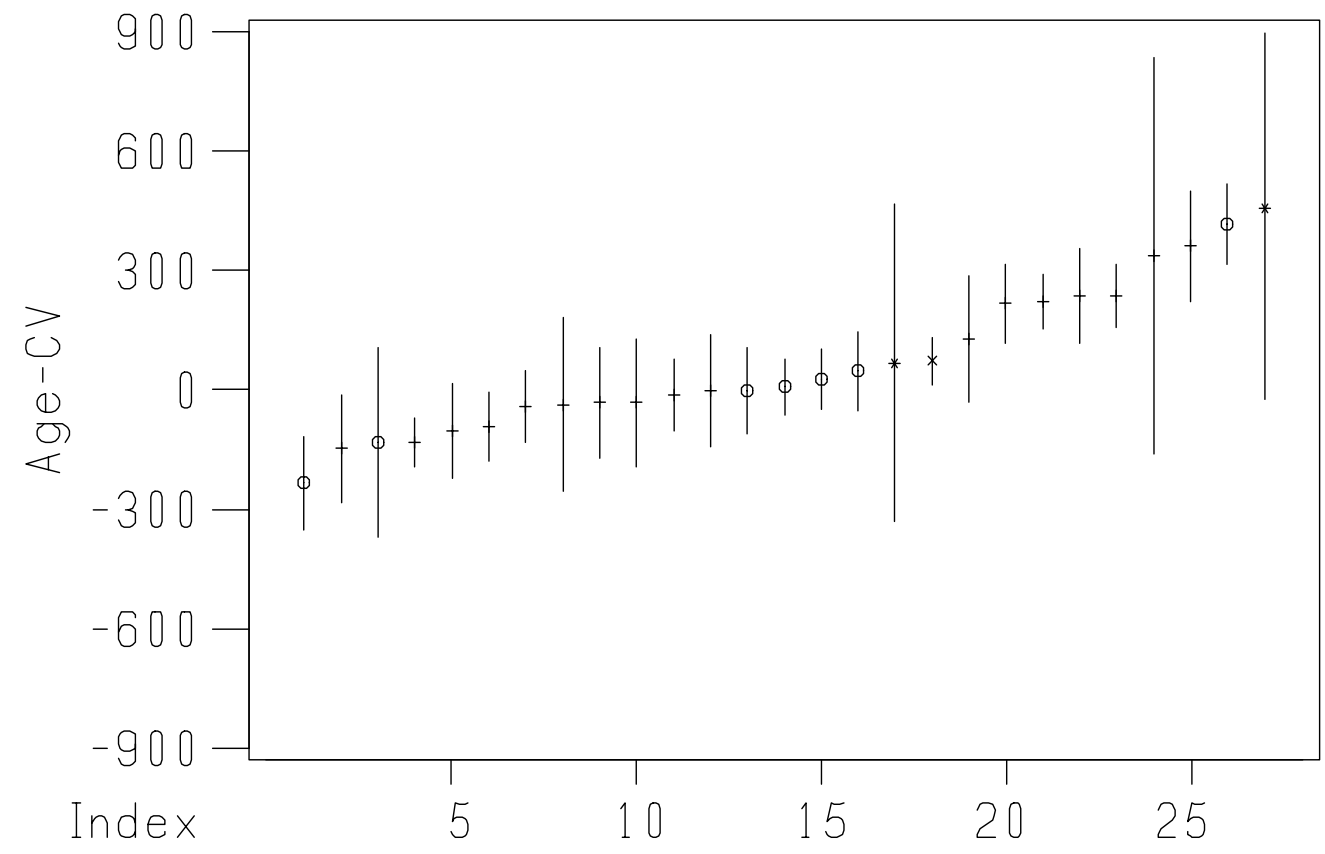

Figure 4.14 Sample M: Icelandic peat

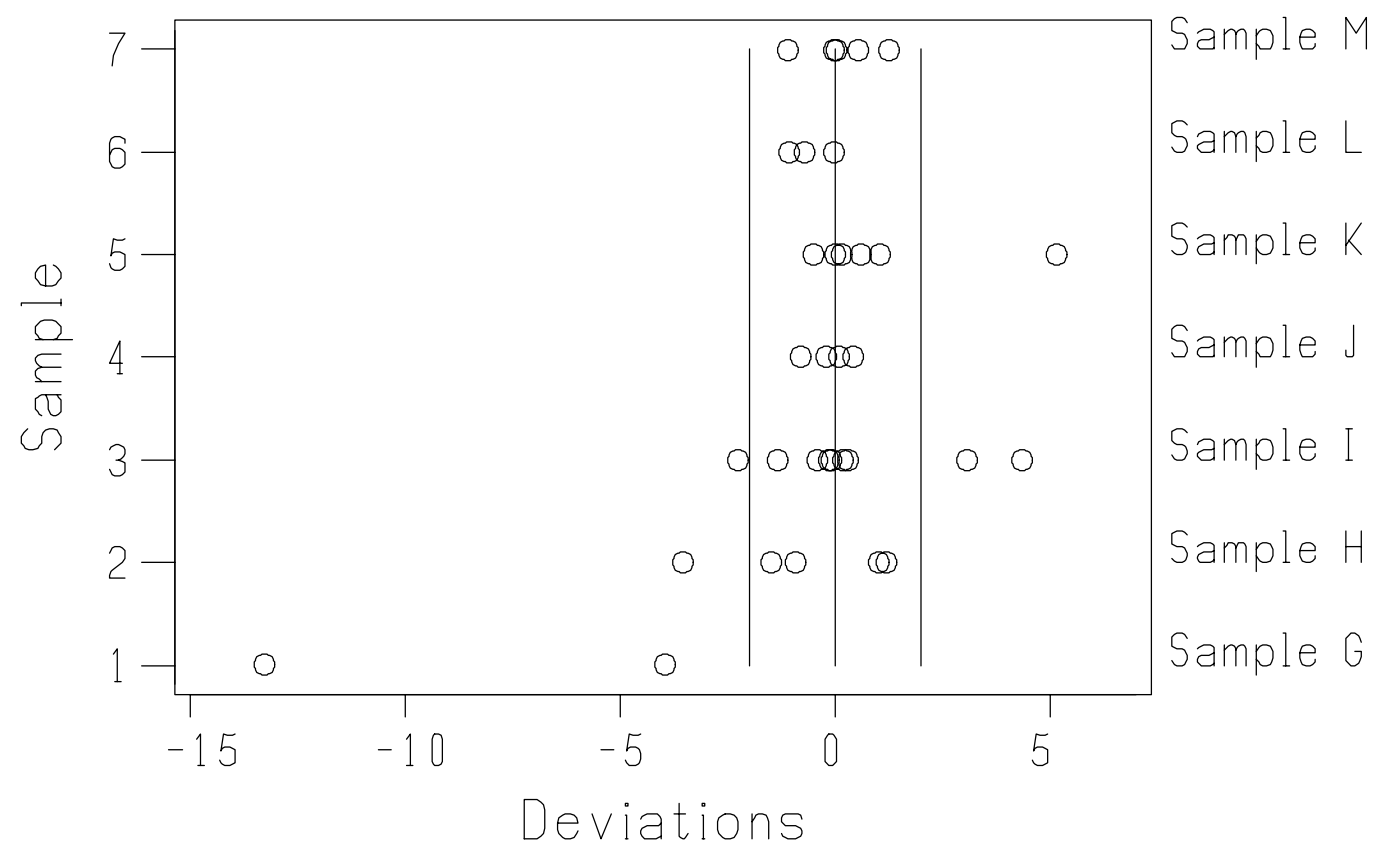

Figure 4.15 Deviations for GPC laboratories by sample 


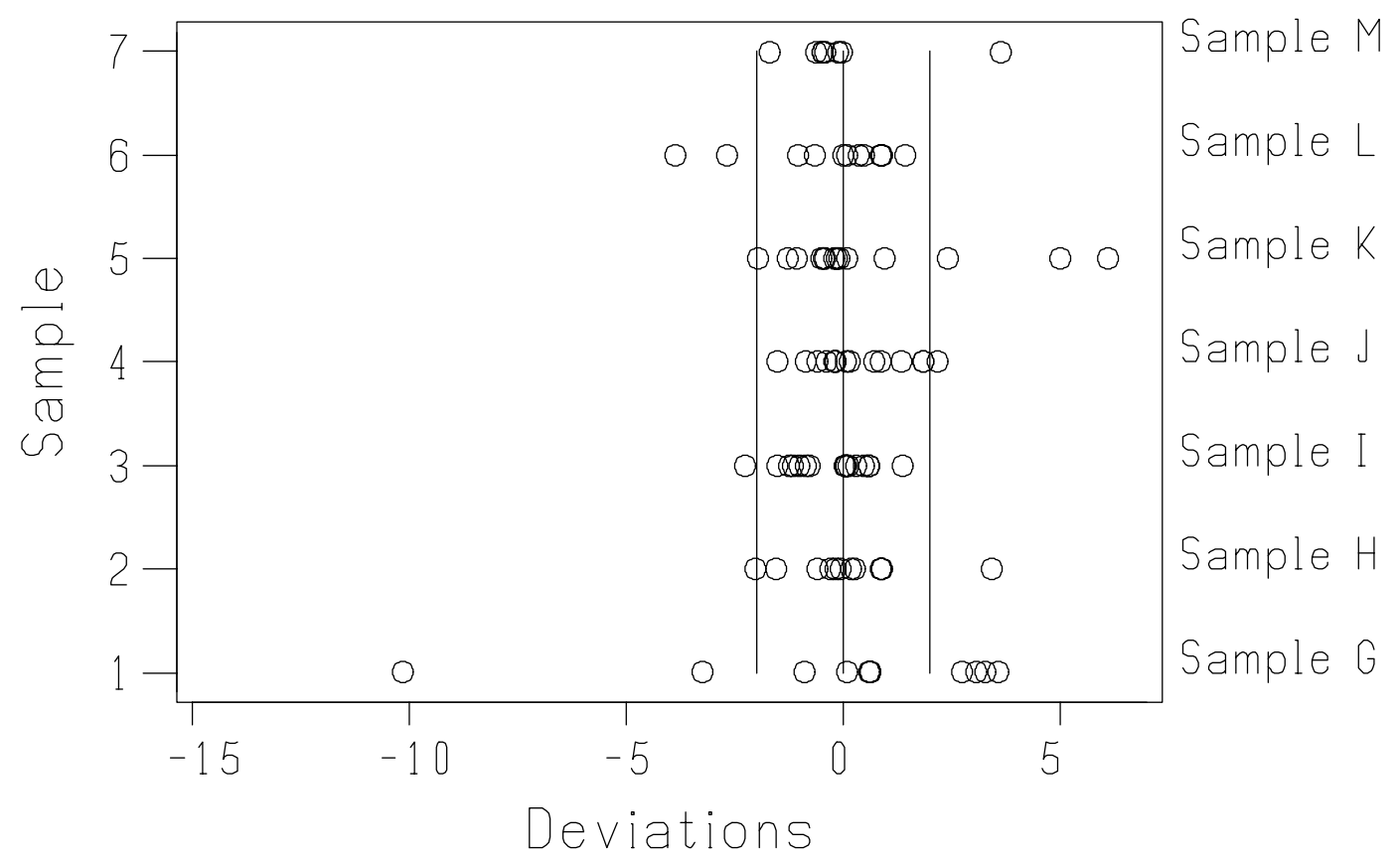

Figure 4.16 Deviations for LSC laboratories by sample

\section{LABORATORY PERFORMANCE}

\subsection{BIAS AND ERROR MULTIPLIERS}

Finally, as a summary of the individual laboratory performance, the relative bias (relative to the consensus values) and the error multiplier have been calculated based on the deviations as calculated for each lab and using results from both core and optional samples.

\section{Measurement Model Used:}

$\mathrm{X}_{\mathrm{ij}}=$ Consensus value $\mathrm{i}_{\mathrm{i}}+\varepsilon_{\mathrm{ij}}$ for $\mathrm{I}=1, . ., \mathrm{N}$ (number of labs) and $\mathrm{j}=1, \ldots, \mathrm{J}$ (number of samples)

where $X_{i j}$ is the ${ }^{14} \mathrm{C}$ age for sample $i$ given by lab $j$ and Consensus value $\mathrm{e}_{\mathrm{i}}$ is the consensus value for sample $i$.

We further assume that $\varepsilon_{\mathrm{ij}}$ is normally distributed with mean 0 and variance $=\mathrm{S}_{\mathrm{ij}}{ }^{2} \sigma_{\mathrm{ij}}{ }^{2}$

where $S_{i j}$ is the quoted uncertainty and $\sigma_{\mathrm{ij}}$ is the error multiplier.

For each laboratory, we first carry out a formal test of a non-zero offset (relative bias) from the consensus values. This corresponds to a simple t-test of the deviations, with the null hypothesis that the mean value is 0 . Eleven laboratories were found (at $5 \%$ level) to have a bias significantly different from zero. An additional 4 laboratories had a bias significantly different from zero (at a 10\% level). For those laboratories for which there is no evidence of a relative bias, the error multiplier is evaluated and formally tested. This formal test simply evaluates whether the error multiplier is equal to 1 . A value of 1 would indicate that the size of the deviations from the consensus value are in agreement with the size of the quoted uncertainties. A 95\% confidence interval for $\sigma_{\mathrm{ij}}$ is calculated based on a $\chi^{2}$ distributional result. 
For those labs without relative bias, the error multiplier, $\sigma_{i}$, has been calculated under the model, assuming no bias, shown below as:

$$
\sigma_{\mathrm{ij}}^{2}=1 / \mathrm{J} \sum \mathrm{d}_{\mathrm{ij}}{ }^{2}
$$

where $\mathrm{d}_{\mathrm{ij}}$ is the deviation for lab $j$ for sample $i$, and $J$ is the total number of samples reported by lab $j$.

Further, a 95\% confidence interval for the error multiplier has also been calculated (the value 1 should lie within this range for laboratories whose deviations from the consensus values agree within their quoted uncertainties).

The results are shown in the Table 5.1: a* value in the table indicates a laboratory with an error multiplier of plausibly 1 .

Table 5.1 Interval estimates for error multiplier for those labs with no relative bias

\begin{tabular}{|c|c|c|c|}
\hline Laboratory & Type & Lower limit & Upper limit \\
\hline 1 & LSC & 0.39314 & $1.5448 *$ \\
\hline 2 & GPC & 0.75462 & $3.6203 *$ \\
\hline 3 & LSC & 1.72561 & 4.5800 \\
\hline 4 & AMS & 1.36298 & 5.3555 \\
\hline 6 & GPC & 3.26318 & 12.8220 \\
\hline 7 & LSC & 3.85350 & 9.2430 \\
\hline 8 & GPC & 2.98044 & 6.6297 \\
\hline 9 & LSC & 1.82828 & 7.1838 \\
\hline 10 & GPC & 2.55963 & 16.8388 \\
\hline 11 & LSC & 1.78315 & 4.4783 \\
\hline 12 & GPC & 1.12415 & 7.3953 \\
\hline 15 & LSC & 3.84395 & 10.2024 \\
\hline 16 & LSC & 0.62025 & $2.9757 *$ \\
\hline 17 & LSC & 2.30556 & 7.0962 \\
\hline 18 & GPC & 1.39678 & 4.7739 \\
\hline 19 & LSC & 0.92575 & $1.6943^{*}$ \\
\hline 20 & LSC & 0.29319 & $1.0021 *$ \\
\hline 21 & LSC & 1.09995 & 3.7594 \\
\hline 22 & GPC & 0.77278 & $1.5439 *$ \\
\hline 23 & GPC & 2.55769 & 6.4235 \\
\hline 24 & AMS & 0.67305 & $1.2318^{*}$ \\
\hline 25 & AMS & 3.22388 & 5.7437 \\
\hline 26 & LSC & 0.60067 & $3.9516^{*}$ \\
\hline 27 & AMS & 0.32694 & $1.1174 *$ \\
\hline 30 & AMS & 0.62148 & $2.4420 *$ \\
\hline 31 & LSC & 1.79200 & 4.7562 \\
\hline 32 & LSC & 2.30850 & 7.8900 \\
\hline 34 & LSC & 1.12385 & 2.9829 \\
\hline 35 & LSC & 1.90813 & 6.5216 \\
\hline 36 & LSC & 3.71198 & 7.9961 \\
\hline 41 & LSC & 0.20635 & $1.3575^{*}$ \\
\hline 42 & LSC & 1.62698 & 4.0861 \\
\hline 43 & LSC & 1.16020 & 2.1234 \\
\hline 45 & GPC & 1.86341 & 7.3219 \\
\hline 47 & LSC & 1.24230 & 2.9774 \\
\hline 48 & LSC & 1.16715 & 3.9891 \\
\hline
\end{tabular}


Table 5.1 Interval estimates for error multiplier for those labs with no relative bias (Continued)

\begin{tabular}{llll}
\hline Laboratory & Type & Lower limit & Upper limit \\
\hline 49 & LSC & 1.06416 & 2.5505 \\
50 & other & 0.71129 & $2.1893^{*}$ \\
51 & LSC & 0.78706 & $2.0890^{*}$ \\
52 & LSC & 1.30224 & 4.0081 \\
53 & GPC & 1.53774 & 2.6762 \\
54 & LSC & 4.17980 & 20.0528 \\
55 & GPC & 0.95746 & $6.2988^{*}$ \\
56 & GPC & 1.40190 & 4.7914 \\
57 & LSC & 1.76777 & 5.4410 \\
58 & LSC & 1.80718 & 4.1622 \\
59 & GPC & 0.46164 & $1.8139^{*}$ \\
60 & LSC & 1.70803 & 5.8377 \\
61 & AMS & 1.81663 & 3.7125 \\
62 & LSC & 0.51584 & $2.0269^{*}$ \\
64 & LSC & 0.59069 & $2.3210^{*}$ \\
66 & AMS & 1.60930 & 6.3234 \\
67 & AMS & 1.71646 & 5.8666 \\
68 & AMS & 0.36383 & $1.4296^{*}$ \\
69 & LSC & 1.79715 & 4.7699 \\
72 & AMS & 1.23534 & 2.5883 \\
74 & LSC & 1.27743 & 3.2080 \\
75 & GPC & 1.08569 & 3.7107 \\
\hline
\end{tabular}

A histogram (Figure 5.1) of the error multipliers is given, as well as a boxplot (Figure 5.2) showing error multipliers by laboratory type. It is clear that the median error multiplier is around 2, suggesting that the quoted uncertainties are, in general, too small. However, it is also the case, that although for each of the laboratories, we have found no statistical evidence of a relative bias, the mean offset may still be non-zero. By ignoring this fact, the error multipliers are, in fact, slightly inflated as a result.

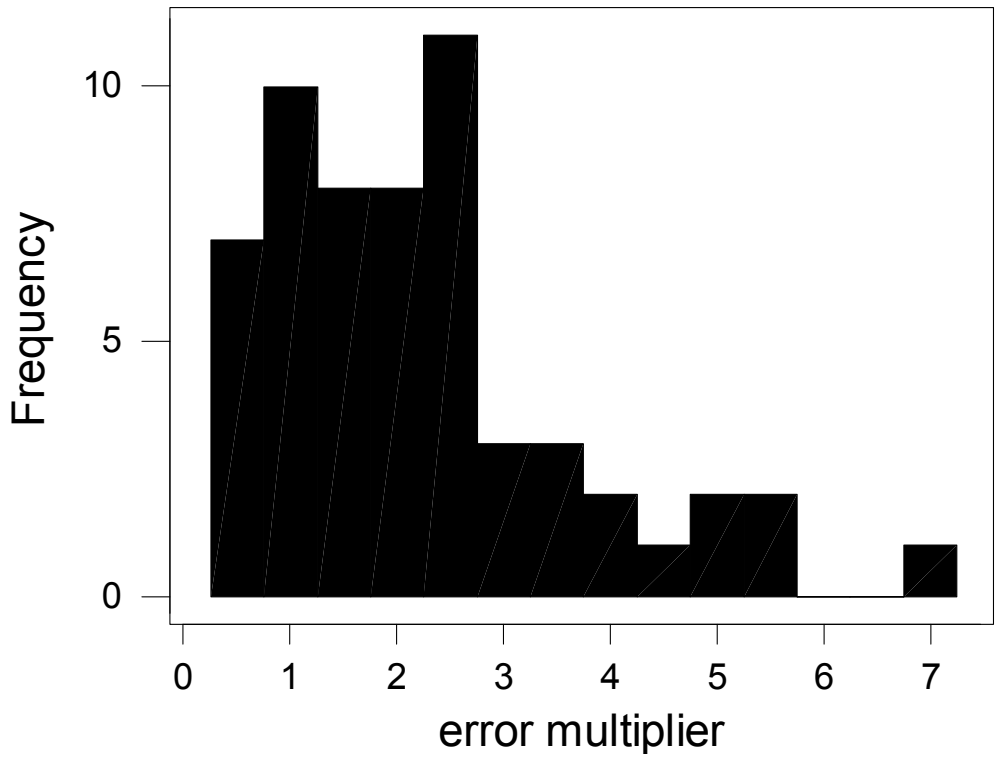

Figure 5.1 Histogram of error multipliers 


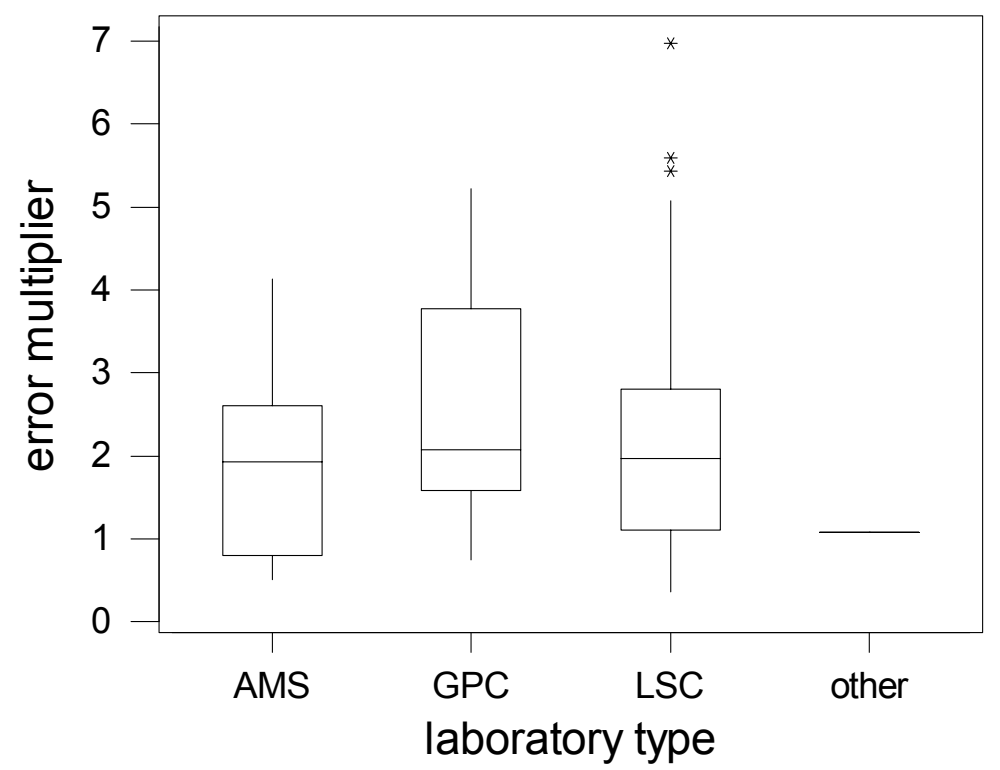

Figure 5.2 Distribution of error multipliers by laboratory type

\section{CONCLUSIONS}

TIRI provided valuable information to laboratories (both well-established and new) and hence, to users. It demonstrated the existence of additional variation (through the error multiplier) in the results, part of which must be due to the natural variation of the samples. Anomalous observations were found, although there is no evidence that they occurred on a frequent basis. There is evidence of significant between-laboratory variation, but no indications of differences in performance amongst the different laboratory types.

In the analysis the error multiplier was used. This is a rather simple tool, which has advantages and disadvantages in its use. Its main advantage is that it is very simple to use, and relates the observed variation in a direct way to the quoted uncertainties. However, it is difficult to meaningfully interpret, at least from the analyst's perspective and it is highly sensitive to anomalous observations. It refers to the results as reported and, thus, may not be generalizable beyond the study to which it refers.

Nevertheless, in TIRI as in the other studies, it points to variation in the results beyond that described by the quoted uncertainties. TIRI was not intended to explore the sources of the variation in the results, but it should be noted that at the TIRI workshop (Gulliksen and Scott 1995), there had been discussion concerning the homogeneity of the test samples, the issues of selection of small samples for AMS dating and the question of differing measured ${ }^{14} \mathrm{C}$ contents depending on the chemical fraction dated. It is clear, that in any study using natural samples some part of the extra variation must be due to the sampling of the bulk material. These issues are ones that will become increasingly important in future dating exercises (see discussion in FIRI on sample homogeneity testing).

Fourteen laboratories were found to have a significant bias, and for 55 laboratories, no such systematic bias was found. For these 55 laboratories, an error multiplier was then evaluated. Of the 55 laboratories, 28 had an error multiplier less than 2, and a significant number of these had an error multiplier less than 1 . 
Consensus values for the materials were derived and are shown in Table 6.1. Some of these materials were archived and re-used in FIRI. A store of material still remains for use by the ${ }^{14} \mathrm{C}$ dating community.

Table 6.1a Consensus values for Stage 1 TIRI samples

\begin{tabular}{lcc}
\hline Sample & Consensus value & Estimated precision $(1 \sigma)$ \\
\hline A: barley mash & $116.35 \mathrm{pMC}$ & 0.0084 \\
B: Belfast pine & 4503 & 6 \\
C: IAEA cellulose & $129.7 \mathrm{pMC}$ & 0.08 \\
D: Hekla peat & 3810 & 7 \\
E: Ellanmore humic & 11,129 & 12 \\
F: Icelandic doublespar & 46,750 & 208 \\
F: Icelandic doublespar & $0.18 \mathrm{pMC}$ & 0.006 \\
\hline \multicolumn{3}{r}{ Table 6.1b Consensus values for Stage 2 TIRI samples } \\
\hline Sample & Consensus value & Estimated precision $(1 \sigma)$ \\
\hline G: Fuglaness wood & 39,784 & 620 \\
H: Ellanmore whole peat & 11,152 & 23 \\
I: travertine & 11,060 & 17 \\
J: Crannog wood & 1605 & 8 \\
K: turbidite carbonate & 18,155 & 34 \\
L: whalebone & 12,788 & 30 \\
M: Icelandic peat & 1682 & 15 \\
\hline
\end{tabular}

It is also of interest to compare the 2 samples that are common in both TIRI and FIRI. These are the TIRI-B and FIRI-D and FIRI-F (Belfast pine), and TIRI-K and FIRI-C (marine turbidite from the same source).

Table 6.2 TIRI and FIRI samples in common

\begin{tabular}{|c|c|c|c|}
\hline Sample description & Consensus value & True age & $\begin{array}{l}\text { Estimated } \\
\text { precision }(1 \sigma)\end{array}$ \\
\hline TIRI-B: Belfast dendro-dated wood & 4503 yr BP & $\begin{array}{l}3200-3239 \mathrm{BC} \\
\left({ }^{14} \mathrm{C} \text { age } 4495 \mathrm{BP}\right)\end{array}$ & 6 \\
\hline FIRI-D, F: Belfast dendro-dated wood & 4508 yr BP & $\begin{array}{l}3200-3239 \mathrm{BC} \\
\left({ }^{14} \mathrm{C} \text { age } 4495 \mathrm{BP}\right)\end{array}$ & 3 \\
\hline TIRI-K: turbidite & 18,155 yr BP & - & 34 \\
\hline FIRI-C: turbidite & 18,176 yr BP & - & 10.5 \\
\hline
\end{tabular}

The consensus values, as estimated from the 2 different studies, are virtually identical. The estimated precisions are different. This is likely due to 3 reasons: a) the larger number of laboratories that participated in FIRI compared to TIRI; b) the tighter screening criteria used in FIRI; and c) the reduced scatter in the set of measurements once outliers have been removed.

\section{REFERENCES}

Gulliksen S, Scott EM. 1995. Report on TIRI workshop. Radiocarbon 37(2):820-1.

Rozanski K, Stichler W, Gonfiantini R, Scott EM, Beukens RP, Kromer B, van der Plicht J. 1992. The IAEA

${ }^{14} \mathrm{C}$ intercomparison exercise 1990. Radiocarbon
34(3):506-19.

Scott EM, Aitchison TC, Harkness DD, Cook GT, Baxter MS. 1990. An overview of all three stages of the international radiocarbon intercomparison. Radiocarbon 32(3):309-19. 